\title{
NUMERICAL ANALYSIS OF TIME-DEPENDENT BEHAVIOUR FOR THE LEANING TOWER OF PISA
}

\author{
J. BAi ${ }^{\text {i) }}$ D. CHAN ${ }^{\text {ii) }}$ and N. MoRGENSTERN ${ }^{\text {iii) }}$
}

\begin{abstract}
This study investigates the significance of the creep characteristic in the deformation behaviour of the Pisa Tower through the simulation of creep tests as well as plane strain analyses conducted under non-creep and creep conditions. Creep effects account for up to 1.7 degrees of tilting and one meter of settlement. In addition, creep increases the mean effective stresses and decreases the deviatoric stresses in the clay layers. An extensive model parameter sensitivity study shows that the deformation behaviour of the Tower is not controlled by any specific model parameter, but each model parameter becomes more sensitive under high stress level. The total tilt of 5.5 degrees could not be achieved by simply changing the values of model parameters. Other factors may have also contributed to the deformation of the tower, which could not be considered by the current model.
\end{abstract}

Key words: constitutive model, creep, finite element, numerical analysis, Pisa soil, Pisa Tower, sensitivity, settlement, tilting (IGC: E2)

\section{INTRODUCTION}

The Leaning Tower of Pisa is one of the most fascinating problems that geotechnical engineers have ever faced. During the last 800 years, the south side of the tower has settled more than the north side, which resulted in about 2 meters of differential settlement and 5.5 degrees of southward tilting. The seventh cornice presently overhangs the first one by 4.1 meters. The factor of safety against overturning failure is very close to one. If the tower continues to tilt, it may collapse catastrophically in the near future. In order to save the tower, various stabilisation measures have been proposed. The temporary application of a $6 \mathrm{MN}$ lead counterweight at the north rim of the tower base has reversed the tilting by 50 seconds of arc. Additional measures are being implemented to provide a more permanent solution. Meanwhile, numerous studies have been made in an effort to understand the deformation mechanisms of the soil beneath the foundation (e.g., Mitchell et al., 1977; Lenonards, 1979; Burland and Potts, 1995; Mitchell and Soga, 1995). However, they all failed to quantify the soil creep effects on the deformation behaviour of the tower, although creep tests conducted by Bishop and Lovenbury (1969) and Mitchell and Soga (1995) have concluded the importance of the creep characteristic in the Pisa clay.

Creep in soils has been studied for five decades. Various creep models have been developed based on different mechanisms (Buisman, 1940; Barden, 1969), such as vis- cous soil skeleton (Murayama and Shibata, 1958; Christensen and Wu, 1964; Yoshikuni et al., 1994); jumping of bonds (Eyring, 1936; Murayama and Shibata, 1961; Mitchell, 1964; Kuhn and Mitchell, 1993); structural viscosity (Terzaghi, 1941; Barden, 1965; Walker, 1969); and micropore-macropore structure (De Jong, 1968; Holzer et al., 1973). Most of these creep models still remain at research levels. The time-dependent constitutive model that is used here belongs to the phenomenological model developed by Borja and Kavazanjian (1985) and Hsieh et al. (1990). It has been successively used in certain field cases (Borja et al., 1990; Brandes et al., 1994; Morsy et al., 1995).

In this study, simulation of creep tests was first undertaken. Then non-creep and creep analyses were carried out in order to quantify the creep effects on the deformation behaviour of the tower throughout its 800-year history. Lastly, a sensitivity study was carried out to study the degree that the model parameter would affect the calculations.

\section{THE LEANING TOWER OF PISA}

The tower was constructed to complete a religious monument complex, which includes the Cathedral and the Baptistery. The Cathedral was erected one hundred years earlier and the Baptistery twenty years before the commencement of the tower. The tower is about 60 meters high with a foundation diameter of 20 meters, as

i) Senior Civil Engineer, Engineering Department, The Metropolitian Water Reclamation of Greater Chicago, Chicago, USA.

ii) Professor, Department of Civil \& Environmental Engineering, University of Alberta, Canada (dave.chan@ualberta.ca).

iii) Professor Emeritus, ditto.

The manuscript for this paper was received for review on May 17, 2006; approved on February 5, 2008.

Written discussions on this paper should be submitted before November 1, 2008 to the Japanese Geotechnical Society, 4-38-2, Sengoku, Bunkyo-ku, Tokyo 112-0011, Japan. Upon request the closing date may be extended one month. 


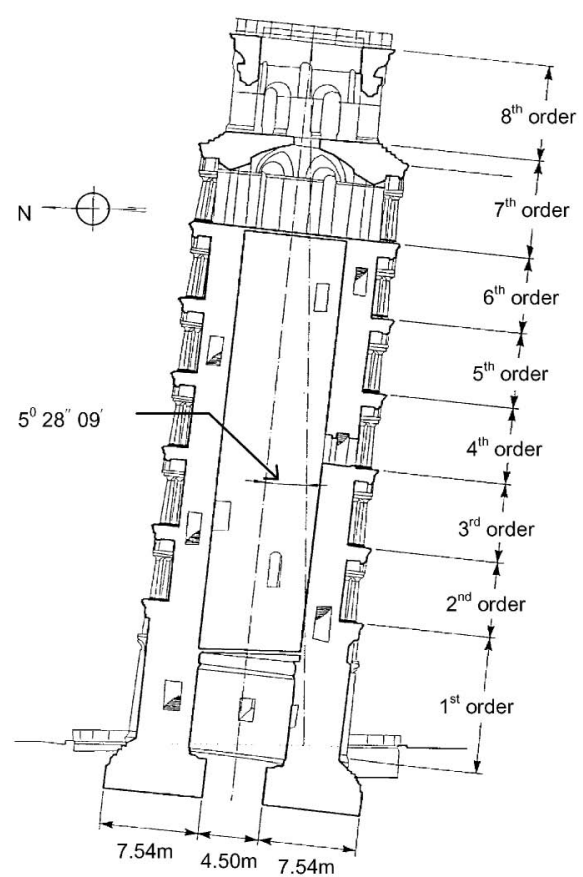

Fig. 1. Geometrical characteristics of Pisa Tower (modified after Jamiolkowski et al., 1993)

shown in Fig. 1. It was constructed in three stages. The first stage started in 1173. By 1178, it reached the fourth storey and then the work was stopped. The second stage started in 1272 and ended in 1278. It brought the tower to the seventh storey and then the work was stopped again. The third construction stage started in 1360 and in 1370, the bell tower was finally finished. It was clear that if the construction continued without any interruption, the foundation soil would have experienced an undrained bearing capacity failure.

Figure 2 shows the ground profile underlying the tower. There are three distinct formations: the $10 \mathrm{~m}$ thick Formation A consists of rather variable sandy and clayey silts. The material in the south side of the tower appears to be more silty and clayey than in the north side. This is believed to be a major factor in causing the tower to lean in a southern direction; the $30 \mathrm{~m}$ thick Formation B contains predominantly clay. It includes the upper clay or Pancone clay $\left(B_{1}\right.$ to $\left.B_{3}\right)$, the intermediate clay $\left(B_{4}\right.$ to $\left.B_{5}\right)$, the intermediate sand $\left(B_{6}\right)$, and the lower clay $\left(B_{7}\right.$ to $\left.B_{10}\right)$; and Formation $C$, encountered at a depth of $40 \mathrm{~m}$, contains slightly silty sand. It extends to a depth greater than the deepest boring.

Drained triaxial creep tests conducted by Bishop and Lovenbury (1969) and Mitchell and Soga (1995) revealed large creep deformations in the upper clay layers, which suggested that creep deformations may have contributed to a significant portion of the present tilting for the tower. On the other hand, a survey of literature shows that creep characteristics have not been incorporated into any numerical models to study the deformation mechanism of the Pisa soil.

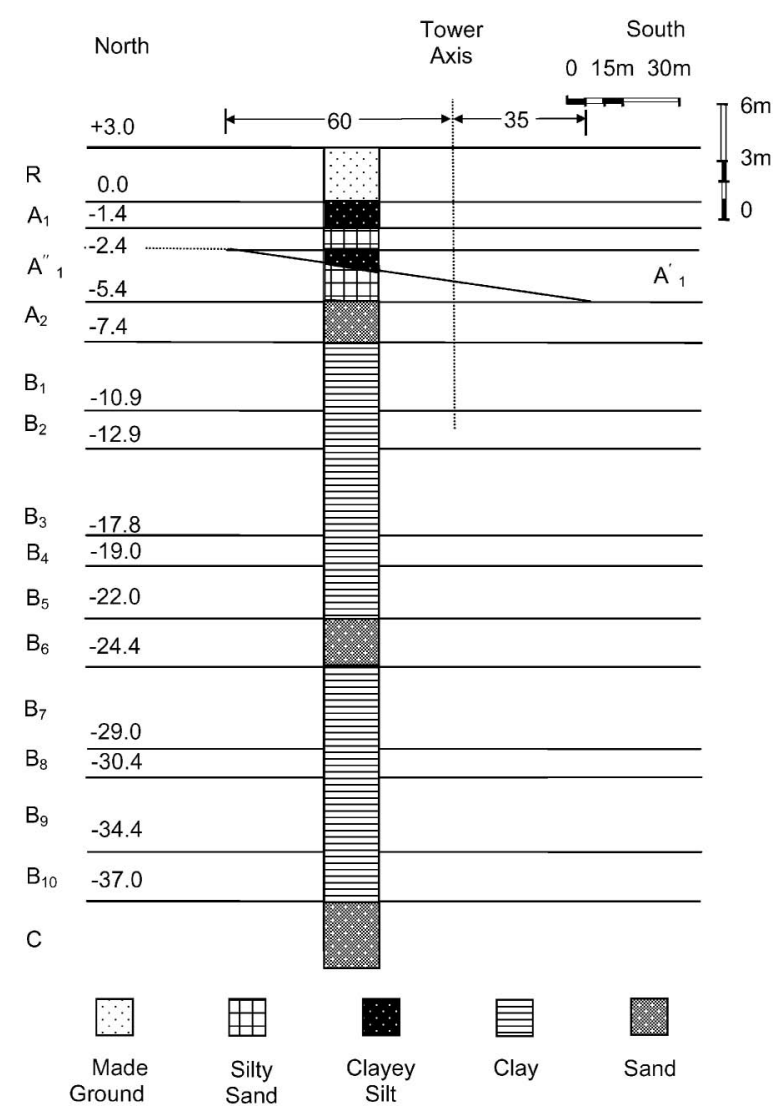

Fig. 2. Probable initial soil profile at the site of Pisa Tower (modified after Calabresi et al., 1992)

\section{TIME-DEPENDENT CONSTITUTIVE MODEL}

The double-yield surface Cam-clay plasticity (DYSCP) model developed by Hsieh et al. (1990) has been adopted in this study due to its simplicity and successful application in field cases (Borja et al., 1990; Brandes et al., 1994; Morsy et al., 1995). Thirteen material parameters are required to fully define the model. Seven parameters are necessary for complete material definition in the absence of creep and six more are required for creep characteristics. These parameters are all readily obtainable from standard laboratory tests or correlation with index properties of the soil. A detailed derivation of this model can be found in Hsieh et al. (1990), Morsy (1994), and Bai (1998). Only the main features and the relevant equations are presented.

The model employs the concept of double-yield criteria that is defined by the ellipsoid modified Cam-clay model (MCCM) and the Von-Mises cylinder inscribed in the ellipsoid, as shown in Fig. 3. The yield functions $F$ for the MCCM and $G$ for the von-Mises cylinder are given by Eqs. (1) and (2).

$$
\begin{aligned}
& F=F\left(\sigma_{\mathrm{ij}}^{\prime}, p_{\mathrm{c}}^{\prime}\right)=\frac{q^{2}}{M^{2}}+p^{\prime}\left(p^{\prime}-p_{\mathrm{c}}^{\prime}\right)=0 \\
& G=G\left(\sigma_{\mathrm{ij}}^{\prime}, q_{\mathrm{c}}\right)=q-q_{\mathrm{c}}=0
\end{aligned}
$$

where $\sigma_{\mathrm{ij}}^{\prime}$ are the effective stress components; $\mathrm{M}$ is the 


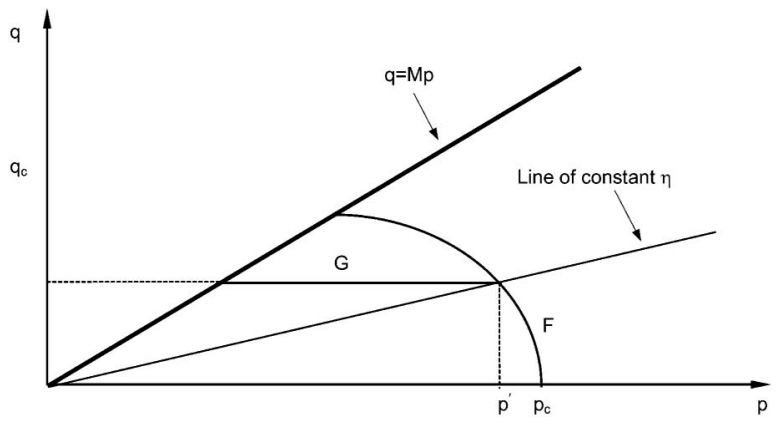

Fig. 3. Projection of double yield surface on $p-q$ plane

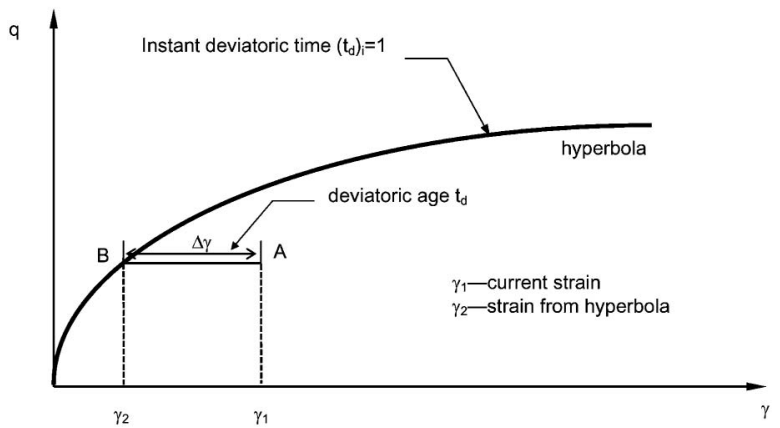

Fig. 4. Projection of double yield surface on $p-\gamma$ plane

slope of the critical state line in the $p^{\prime}-q$ plane; $p^{\prime}$ is the mean effective stress

$$
\left(p^{\prime}=\frac{\sigma_{1}^{\prime}+\sigma_{2}^{\prime}+\sigma_{3}^{\prime}}{3}\right)
$$

$q$ is the deviatoric stress

$$
\left(q=\frac{1}{\sqrt{2}} \sqrt{\left(\sigma_{1}^{\prime}-\sigma_{2}^{\prime}\right)^{2}+\left(\sigma_{2}^{\prime}-\sigma_{3}^{\prime}\right)^{2}+\left(\sigma_{3}^{\prime}-\sigma_{1}^{\prime}\right)^{2}}\right) ;
$$

$p_{\mathrm{c}}^{\prime}$ is the isotropic preconsolidation pressure which controls the size of the $F$ surface; and $q_{\mathrm{c}}$ is the shear yield stress which controls the size of the $G$ surface. The trace of the MCCM surface on the $q-\gamma$ plane, where $\gamma$ denotes the shear strain, is assumed to be a hyperbola, as shown in Fig. 4.

The total strain-rate tensor can be decomposed into four components (Borja and Kavazanjian, 1985; Hsieh et al., 1990; Morsy, 1994)

$$
\underline{\dot{\varepsilon}}=\underline{\dot{\varepsilon}}^{\mathrm{e}}+\dot{\dot{\varepsilon}}_{\mathrm{F}}^{\mathrm{p}}+\underline{\dot{\varepsilon}}_{\mathrm{G}}^{\mathrm{p}}+\underline{\dot{\varepsilon}}^{\mathrm{t}}
$$

where superscripts $e$ and $p$ denote the immediate elastic and plastic parts, respectively; and superscript $t$ denotes the delayed or creep part. $\underline{\dot{\varepsilon}}^{\mathrm{e}}$ is evaluated by applying the generalised Hooke's law. $\underline{\dot{\varepsilon}}_{\mathrm{F}}^{\mathrm{p}}$ and $\dot{\varepsilon}_{\mathrm{G}}^{\mathrm{p}}$ are evaluated according to the yielding surfaces $F$ and $G$, which may move separately, depending on the nature of the stress path. The total creep strain-rate tensor $\dot{\varepsilon}^{t}$ can be further divided into distinct, but interdependent volumetric and deviatoric parts (Kavazanjian and Mitchell, 1980)

$$
\underline{\dot{\varepsilon}}^{\mathrm{t}}=\underline{\dot{\varepsilon}}_{\mathrm{v}}^{\mathrm{t}}+\underline{\dot{\varepsilon}}_{\mathrm{d}}^{\mathrm{t}}
$$

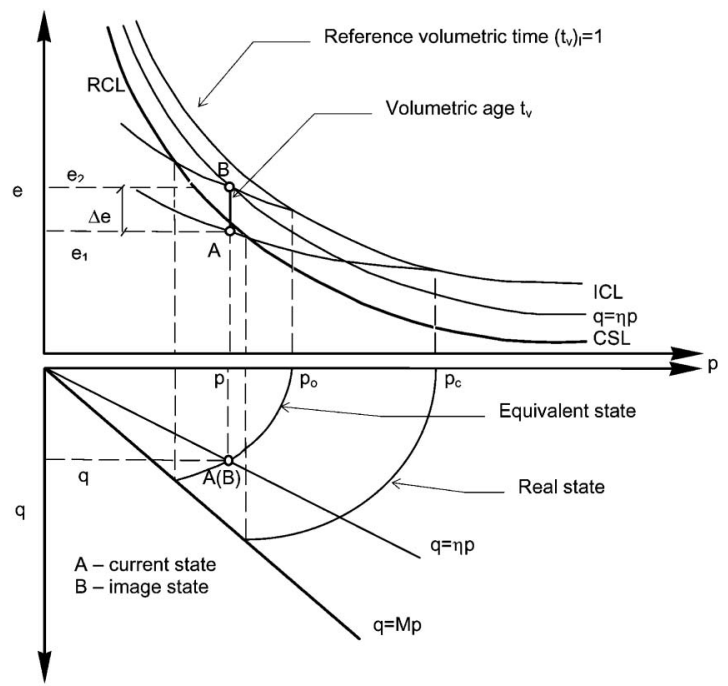

Fig. 5. Evaluation of volumetric age (modified after Borja and Kavazanjian, 1985)

where subscripts $\mathrm{v}$ and $\mathrm{d}$ denote volumetric and deviatoric creep components, respectively. $\underline{\dot{\varepsilon}}^{t}$ can be evaluated through the Taylor's (1948) secondary creep law for volumetric creep and the Singh and Mitchell's (1968) law for deviatoric creep and by employing an associated flow rule for both the equivalent volumetric and deviatoric yield surfaces $F$ and $G$. The resulting creep strain is neither perpendicular to $F$ nor to $G$ and therefore, the flow rule for the creep strains is always non-associative. The creep strain is given by:

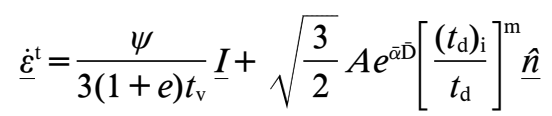

where $\underline{I}$ denotes the second-order identity tensor;

$$
\hat{n}=\frac{\sigma^{\prime}}{\left\|\underline{\sigma}^{\prime}\right\|} ;
$$

and \|\| denotes the Euclidean norm; $\psi$ denotes the secondary compression coefficient, in natural logarithm scale; e denotes the void ratio; $t_{\mathrm{v}}$ and $t_{\mathrm{d}}$ denote the volumetric age relative to $\left(t_{\mathrm{v}}\right)_{\mathrm{i}}$ and deviatoric age relative to $\left(t_{\mathrm{d}}\right)_{\mathrm{i}}$ as shown in Figs. 5 and 4, respectively; $\left(t_{\mathrm{v}}\right)_{\mathrm{i}}$ and $\left(t_{\mathrm{d}}\right)_{\mathrm{i}}$ denote the initial volumetric and deviatoric times, usually set to unity; $A, \bar{\alpha}$, and $m$ denote the Singh and Mitchell creep parameters, as shown in Fig. 6; and $\bar{D}$ denotes the deviatoric stress level,

$$
\bar{D}=\frac{\left(\sigma_{1}-\sigma_{3}\right)}{\left(\sigma_{1}-\sigma_{3}\right)_{\mathrm{ult}}} ;
$$

The volumetric age $t_{\mathrm{v}}$, a measure of void ratio reduction due to creep; determines the growth rate of $p_{c}^{\prime}$. The deviatoric age $t_{\mathrm{d}}$, a measure of the shear strain change due to overconsolidation, determines the growth rate of $q_{\mathrm{c}} . t_{\mathrm{v}}$ and $t_{\mathrm{d}}$ can be represented in the following equations (Bai, 1998):

$$
t_{\mathrm{v}}=\left(t_{\mathrm{v}}\right)_{\mathrm{i}} \exp \left(\frac{e_{2}-e_{1}}{\psi}\right)
$$




$$
\begin{array}{ll}
t_{\mathrm{d}}=\left[\frac{\left(\gamma_{1}-\gamma_{2}\right)(1-m)}{A \exp (\bar{\alpha} \bar{D})\left(t_{\mathrm{d}}\right)_{\mathrm{i}}^{\mathrm{m}}}+\left(t_{\mathrm{d}}\right)_{\mathrm{i}}^{1-\mathrm{m}}\right]^{1 / 1-\mathrm{m}} & \text { for } m \neq 1 \\
t_{\mathrm{d}}=\left(t_{\mathrm{d}}\right)_{\mathrm{i}} \exp \left(\frac{\left(\gamma_{1}-\gamma_{2}\right)}{A \exp (\bar{\alpha} \bar{D})\left(t_{\mathrm{d}}\right)_{\mathrm{i}}}\right) & \text { for } m=1
\end{array}
$$

definitions of $e_{1}, e_{2}, \gamma_{1}$, and $\gamma_{2}$ are shown in Figs. 4 and 5. Equation (7) is different from the previous studies (Borja and Kavazanjian, 1985; Hsieh et al., 1990). Detailed derivation can be found in APPENDIX A.

\section{SIMULATION OF THE CREEP TESTS}

In order to calibrate the constitutive model, the triaxial drained creep tests of Pisa clay conducted by Bishop and Lovenbury (1969) and Mitchell and Soga (1995) were simulated using the finite element program named PISA ${ }^{\circledR}$ (2007). PISA ${ }^{\circledR}$ is a displacement based finite element program capable of performing two and three dimensional

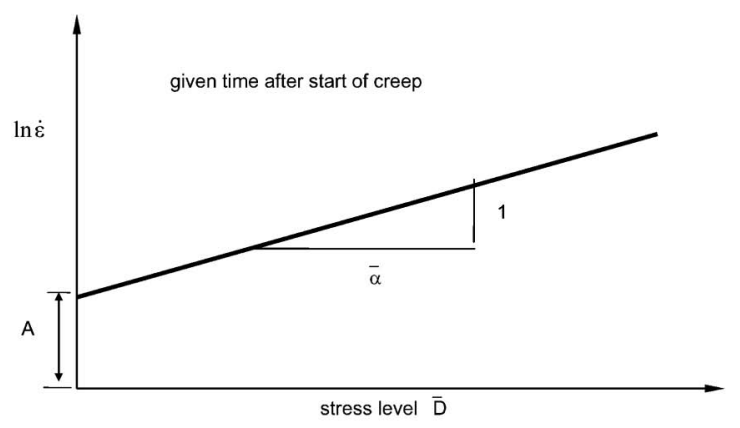

(a)

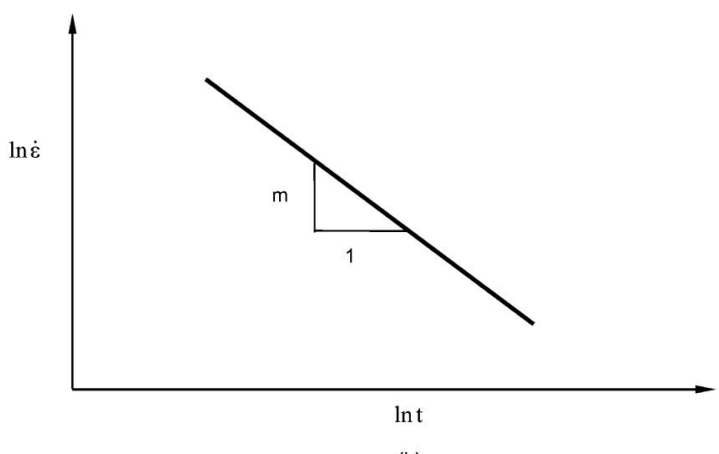

Fig. 6. Singh and Mitchell creep parameters: (a) parameter $A$ and $\bar{\alpha}$; (b) parameter $m$ time dependent analysis of soils. There is a variety of constitutive model in the program which includes the classical elasticity and plasticity models, such as Mohr Coulomb and Drucker and Prager models using associated and non-associated flow rules, the critical state models such as Cam Clay and Modified Cam Clay models, the time dependent model based on Singh-Mitchell creep relationships etc. The program uses an implicit iterative scheme to obtain a solution for non-linear problems. In modelling the creep tests, four eight-node elements were used, as shown in Fig. 7.

The values of the thirteen model parameters are shown in Table 1. Parameters $C_{\mathrm{c}}, C_{\mathrm{r}}, \phi$, and $e_{\mathrm{a}}$ were determined based on Calabresi's (1992) and Tamagnini's (1993) study; Parameters $C_{\mathrm{c}}$ and $C_{\mathrm{r}}$ are determined from the normal consolidation line and rebound line of the compression curve. Friction angle $\phi$ is determined from the MohrCoulomb failure envelop. The Singh and Mitchell parameters $A, \bar{\alpha}$, and m can be determined by plotting log of the strain rates versus log time. This is because taking the $\log$ on both sides of Eq. (5) gives the equation of a straight line, provided that the time dependent response of the material follows the Singh and Mitchell creep relationship. The slope of the line is equal to $\mathrm{m}$ and the intercept is related to $A$. In order to determine $\alpha$, it is necessary to conduct tests at different stress levels. The

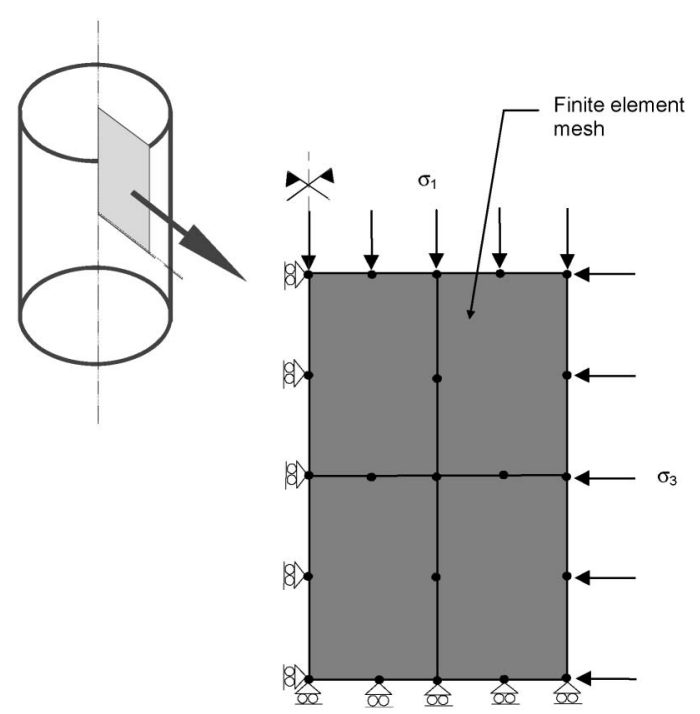

Fig. 7. Numerical simulation of triaxial test on Pisa clay

Table 1. Model parameters

\begin{tabular}{l|c|c|c}
\hline \multicolumn{1}{c|}{ Parameter } & Symbol & $19 \mathrm{~m}$ sample & $10 \mathrm{~m}$ sample \\
\hline Virgin compression index & $C_{\mathrm{c}}$ & $0.515(0.615)$ & 0.615 \\
Recompression index & $C_{\mathrm{r}}$ & 0.081 & 0.081 \\
Secondary compression coefficient & $C_{\alpha}$ & 0.0154 & 0.0154 \\
Hyperbolic parameters & $a, b, R_{\mathrm{f}}$ & $0.0057,1.348,0.80$ & 0.021 \\
Singh and Mitchell creep parameters & $A, \bar{\alpha}, m$ & $2.15^{*} 10^{-3} \% / \mathrm{min}, 8.82,0.95(0.75)$ & $1.62^{*} 10^{-2} \% / \mathrm{min}, 6.33,0.83$ \\
Internal friction angle & $\phi$ & 26.54 & 0.0051 \\
Void ratio at $p_{\mathrm{c}}=1 \mathrm{kPa}$ & $e_{\mathrm{a}}$ & 2.73 & 26.54 \\
Instant volumetric and deviatoric time & $\left(t_{\mathrm{v}}\right)_{\mathrm{i}},\left(t_{\mathrm{d}}\right)_{\mathrm{i}}$ & $1.0 \mathrm{day}, 1.0$ day & $2.73 / \mathrm{min}, 5.86,0.95$ \\
& & 33.67 \\
\end{tabular}


values of these parameters were obtained from Mitchell and Soga's (1995) undrained triaxial tests.

For the parameter $C_{\alpha}$, volumetric creep tests or one dimensional creep tests are required. The value of $C_{\alpha}$ can be determined from secondary compression when consolidation tests are carried out beyond primary consolidation. The value of $C_{\alpha}$ used in this study was determined from Mitchell and Soga's (1995) drained creep tests. The hyperbolic parameters $a$ and $b$ were calculated from the following equations:

$$
\begin{aligned}
& a=\frac{p_{\mathrm{c}}^{\prime} \cdot R_{\mathrm{f}}}{3 G} \\
& b=R_{\mathrm{f}} \cdot \frac{2^{\left(1-\frac{C_{\mathrm{r}}}{C_{\mathrm{c}}}\right)}}{M}
\end{aligned}
$$

where $p_{\mathrm{c}}^{\prime}$ is the preconsolidation pressure; $G$ is the shear modulus; $M$ is the Cam-clay parameter,

$$
M=\frac{6 \sin \phi^{\prime}}{3-\sin \phi^{\prime}}
$$

and $R_{\mathrm{f}}$ is the failure ratio,

$$
R_{\mathrm{f}}=\frac{\left(\sigma_{1}-\sigma_{3}\right)_{\text {failure }}}{\left(\sigma_{1}-\sigma_{3}\right)_{\mathrm{ultimate}}},
$$

it is in the range of 0.7 to 1.0 .

\section{Drained Creep Tests by Bishop and Lovenbury}

Bishop and Lovenbury (1969) studied the creep characteristic of the $19 \mathrm{~m}$ deep Pisa clay, which belongs to the highly structured layer B3 as shown in Fig. 2. Six drained creep tests were conducted under constant loads of 50 , 75 , and $85 \%$ of the drained strength of the clay; two tests for each stress level. The applied confining pressure was $152 \mathrm{kPa}$. The samples were approximately $7.6 \mathrm{~cm}$ in diameter and $15.2 \mathrm{~cm}$ in height. Primary consolidation ended in less than two days after the final load was applied. Test results showed that due to the structural breakdown of the Pisa clay carbonates, all samples exhibited sudden increases in strains for a period of time at some stages. After the structural breakdown, the axial strain rates were in the range of 1 to $1.5 \%$ per logarithmic time cycle.

Simulations of Bishop and Lovenbury's drained creep tests were conducted under three constant loads, as mentioned above. The time period was specified in terms of days. The model parameters are listed in Table 1. The Atterberg limits of these samples are indicated in Table 2. Due to the difference in the Atterberg limits, the value of
$C_{\text {c }}$ was decreased from 0.615 to 0.515 and the value of $\mathrm{m}$ increased from 0.75 to 0.95 to best match the laboratory data.

The results, together with the measured data, are plotted in Figs. 8 and 9. Figure 8 shows an excellent agreement between the numerical and laboratory results for the relationship of axial strain versus time under both $50 \%$ and $75 \%$ stress levels. Under an $85 \%$ stress level, the results under-predict the axial strain, but show the same trend. For the volumetric strain versus time relationship (see Fig. 9), numerical results could not follow the laboratory data precisely. There are two main reasons for the discrepancies. The volumetric strains from laboratory data are unreliable because of leakage problems, as it might be expected from the long duration of the tests. On the other hand, the highly structured nature of the soil could not be considered in the model. However, overall,

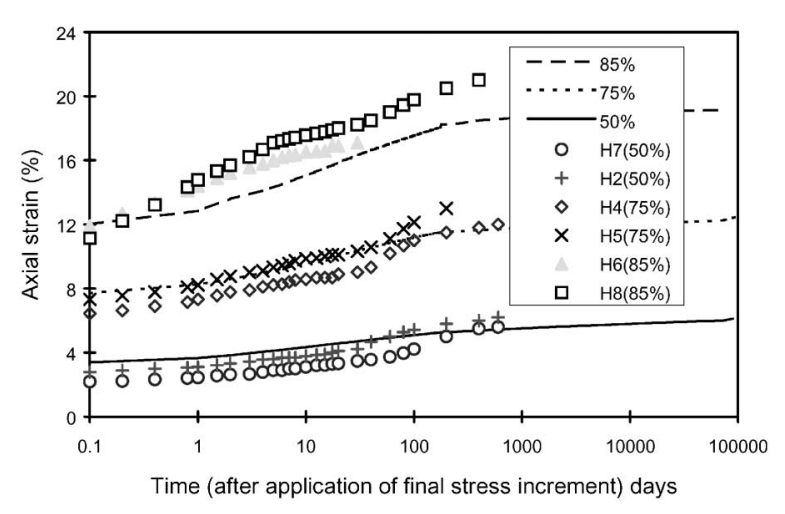

Fig. 8. Axial strain versus time relationship

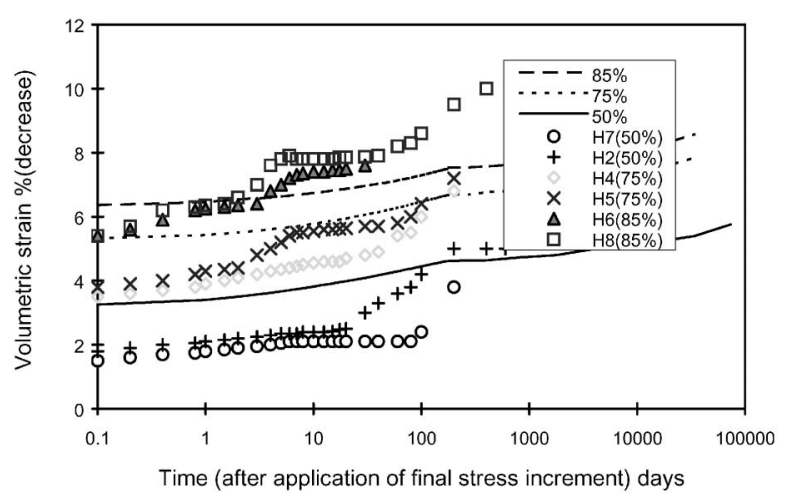

Fig. 9. Volumetric strain versus time relationship

Table 2. Atterberg limits of drained creep test samples

\begin{tabular}{c|c|c|c|c|c}
\hline \multirow{2}{*}{ Items } & \multirow{2}{*}{$\begin{array}{c}\text { Bishop's } \\
\text { test* }\end{array}$} & $\begin{array}{c}\text { Tamagnini's or } \\
\text { Mitchell's test** }\end{array}$ & \multicolumn{2}{|c}{ Mitchell's test } & \multicolumn{2}{c}{ Calabresi's test } \\
\cline { 3 - 6 } & Test-1 (6 m) & Test-2 (10 m) & Test-1 (6 m) & Test-2 (10 m) \\
\hline Water content (\%) & 49.5 & 62 & $28.7-30.6$ & $59.5-66.1$ & $25-33$ \\
Liquid limit (\%) & 76 & 96 & 12.9 & $40-60$ & 36 \\
Plastic limit (\%) & 29 & 41 & 44.5 & 14 \\
\hline
\end{tabular}

* from Table 1, Bishop and Lovenbury (1969);

** from Table 5-1 and 5-2, Mitchell and Soga (1995). 
the numerical results still match the trend of the laboratory data reasonably well.

\section{Drained Creep Tests by Mitchell and Soga}

Mitchell and Soga (1995) conducted a total of nine triaxial drained creep tests for Pisa clay. The samples named Test- 1 to Test-9, were taken at depths of $6 \mathrm{~m}$, $10 \mathrm{~m}, 14 \mathrm{~m}$, and $19 \mathrm{~m}$ corresponding to layers $\mathrm{A}_{1}, \mathrm{~B}_{1}, \mathrm{~B}_{2}$, and $\mathrm{B}_{3}$, respectively. The cylindrical specimens were approximately $3.4 \mathrm{~cm}$ in diameter and $8.9 \mathrm{~cm}$ in height. Drainage was allowed at the top and bottom of the specimen (one-dimensional flow). Based on the laboratory test conducted by Rampello and Callisto (1998), the permeability of the top $7 \mathrm{~m}$ of soil beneath the Pisa tower is approximately $10^{-8} \mathrm{~m} / \mathrm{s}$. Between 7 and $37 \mathrm{~m}$ depth, the clay layer has a permeability of approximately $2-3 \times$ $10^{-10} \mathrm{~m} / \mathrm{s}$. Below $37 \mathrm{~m}$ lies the sand layer. Since the clay layer has a permeability that is much lower than the soil above and below, the drainage condition can be treated as fully drained both at the top and bottom of the clay layer. Loads were applied in steps to simulate the construction sequence of the tower. For each step, a constant load was applied instantly that lasted for 7 days. The soil became fully drained after one day of loading. Throughout the test, a back pressure of $98 \mathrm{kPa}$ was applied to maintain saturation. Some water leakage was observed during the

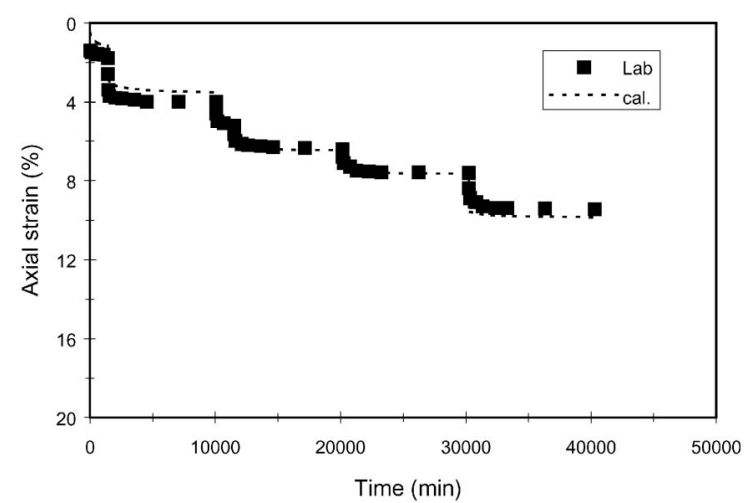

Fig. 10. Axial strain versus time curve for Test-1 6 m sample, layer A1 (Maximum stress case)

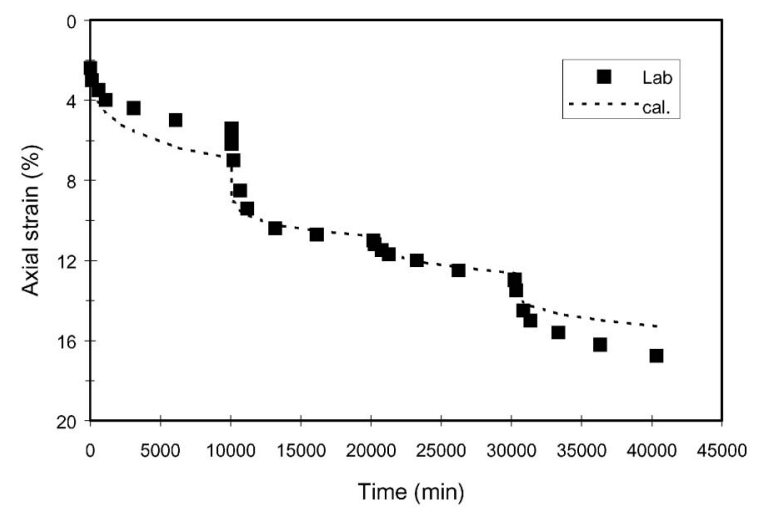

Fig. 11. Axial strain versus time curve for Test-2 $10 \mathrm{~m}$ sample, layer B1 (Maximum stress case) test. Therefore, the volume change data was unreliable.

The sample Test-4 obtained from $19 \mathrm{~m}$ depth was already studied through Bishop and Lovenbury's (1969) creep tests. Creep deformation was not significant for the sample Test-3 at $14 \mathrm{~m}$ depth, due to its relatively low plasticity. Consequently, only simulations of the Test- 1 and Test-2, obtained from $6 \mathrm{~m}$ and $10 \mathrm{~m}$ depths respectively, were conducted. The model parameters are listed in Table 1 and the Atterberg limits are indicated in Table 2. Due to the difference in the Atterberg limits, the compression in$\operatorname{dex} C_{\mathrm{c}}$ of the $6 \mathrm{~m}$ sample was modified from 0.205 to 0.155 to match the laboratory data.

The calculated axial strain versus time relationship is plotted in Figs. 10 and 11. The time for each stage is set in minutes. The numerical results match the laboratory data very well, especially at the second and third stages. There are some discrepancies in the first and the last stages, but the discrepancies are fairly small compared with the total values. The model gives a satisfactory prediction of the stress-strain-time behaviour of the Pisa clay.

\section{PLANE STRAIN ANALYSES}

The observed piezometer results show that the water table in the Pisa soil is between $1 \mathrm{~m}$ to $2 \mathrm{~m}$ below the ground surface and it is quite stable. Therefore, in this study the water table was assumed to be at the ground surface and in a hydrostatic equilibrium condition.

\section{Finite Element Model}

Figure 12 shows a plane strain finite element model, consisting of 425 eight-node quadrilateral isoparametric elements. The mesh represents a vertical plane through the centre of the tower along the N-S direction. It extends horizontally to $60 \mathrm{~m}$ from either side of the tower axis and vertically to $40 \mathrm{~m}$ depth (up to the top of Formation C). Vertical rollers boundaries were used for the left and right sides of the finite element mesh to model far field conditions. Horizontal roller boundary was used for the bottom boundary. The bottom boundary is believed to be sufficiently far enough from the base of the footing so that it has little effect on the settlement of the tower. This is confirmed by the results of the analysis that changes in stresses are small at the bottom boundary in comparison to that under the footing.

In plane strain analysis, the actual three-dimensional rigid annular plate with $19.6 \mathrm{~m}$ outer and $4.5 \mathrm{~m}$ inner diameters needs to be transformed into two rigid plates of infinite length. Those two rigid plates must be connected to prevent them from acting separately (see Fig. 13). The actual applied loads must be converted to loads of unit length through the following equation

$$
\begin{aligned}
& \text { Load (plane strain) })_{\text {South, North }} \\
& =\frac{1}{C F}\left[\frac{\text { Weight }}{2} \pm \frac{\text { Moment. } I_{\mathrm{c}}}{L}\right]
\end{aligned}
$$

where $L$ is the distance between the centre of the two strip footings. $C F$ and $I_{\text {c }}$ are correction factors. Mitchell and 


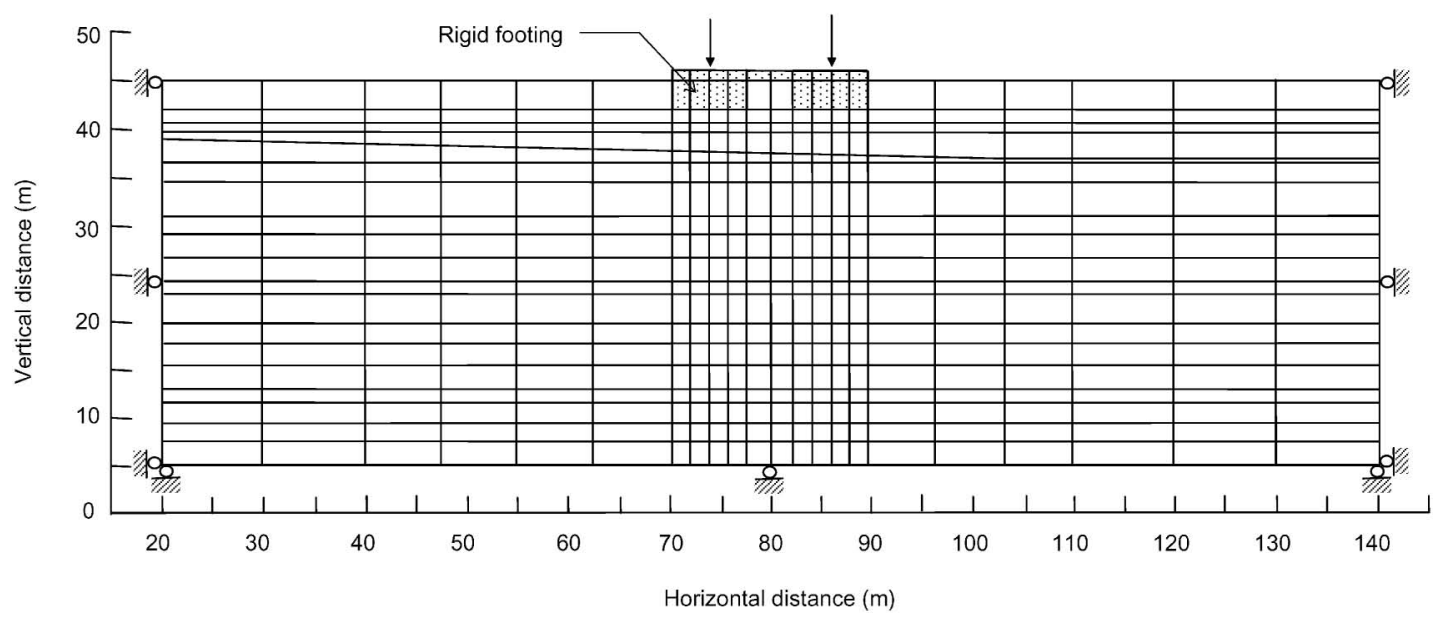

Fig. 12. Finite element mesh for two-dimensional analysis
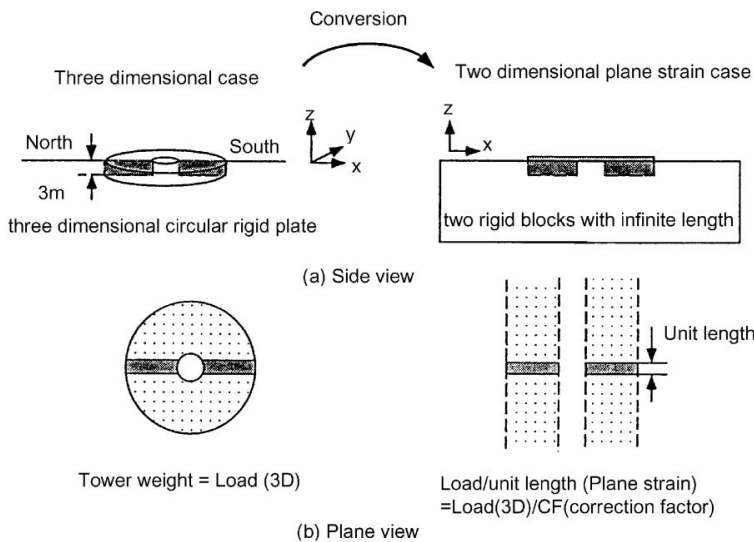

Fig. 13. Conversion of three dimensional condition to plane strain condition (modified after Mitchell and Soga, 1995)

Table 3. Weight, overturning moment and rigid tilt versus time

\begin{tabular}{c|c|c|c}
\hline Year & Weight (MN) & Moment (MNm) & Tilt (degree) \\
\hline 1178 & 94.80 & - & - \\
1272 & 137.28 & 5.51 & 0.103 \\
1360 & 144.53 & 97.7 & 1.611 \\
1990 & 144.53 & 332.56 & 5.469 \\
\hline
\end{tabular}

Soga (1995) found that for the Pisa soil, a better agreement for the stress distribution at shallow depths can be obtained by taking $C F$ of 24 . For a rectangular foundation with a width of $19.6 \mathrm{~m}$ and the same area as the foundation of the tower, Burland and Potts (1995) suggested that the value of $I_{\mathrm{c}}$ is 1.27 .

Table 3 and Fig. 14 show the tower's weight and overturning moment. The actual loads applied to the foundation were obtained by subtracting an amount of 11,589 $\mathrm{kN}$ from the weights of the tower to account for the weight of soil excavated for the tower foundation. Each applied load was converted into two loads using Eq. (10). The two loads were applied at $6.02 \mathrm{~m}$ south and north from the footing centre respectively. The obtained loading conditions relative to different construction stages are

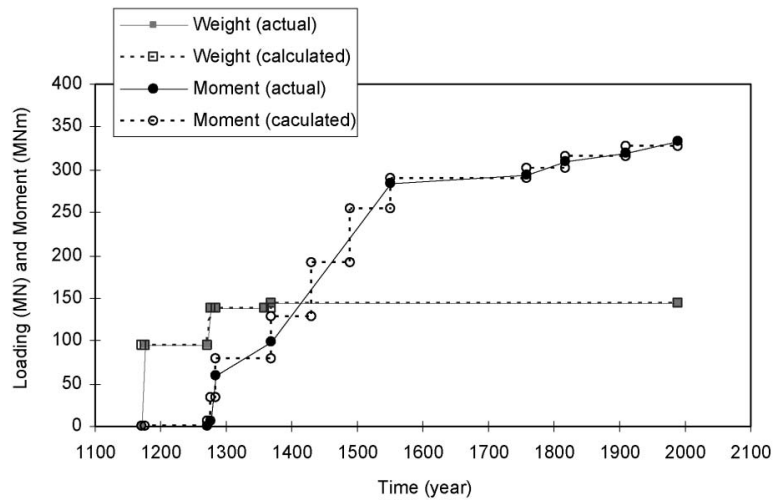

Fig. 14. Pisa Tower's weight and overturning moment versus time

Table 4. Loads for elastic and elasto-plastic analyses $\left(C F=24, I_{\mathrm{c}}=\right.$ 1.27)

\begin{tabular}{c|c|c|r|r}
\hline \multirow{2}{*}{ Year } & \multicolumn{2}{|c|}{$\Delta p(\mathrm{kPa})$} & \multicolumn{2}{c}{$\Delta p / C F(\mathrm{kPa})$} \\
\cline { 2 - 5 } & \multicolumn{1}{|c|}{ North } & South & \multicolumn{1}{c}{ North } & \multicolumn{1}{c}{ South } \\
\hline 1178 & 41605.5 & 41605.5 & 1733.6 & 1733.6 \\
1272 & 20658.8 & 21821.2 & 860.8 & 909.2 \\
1360 & -6100.8 & 13351.2 & -254.2 & 556.3 \\
1990 & -24775.2 & 24775.2 & -1032.3 & 1032.3 \\
\hline
\end{tabular}

Note: $\Delta p$ is the change in applied stress on the foundation.

listed in Table 4. The applied load is converted into vertical stress, $\Delta p$, as shown in Table 4.

The soil parameters used in the elastic analysis are detailed in Table 5. Young's modulus for the rigid footing was chosen at $10^{10} \mathrm{kPa}$, as suggested by Mitchell and Soga (1995). The input data used in elasto-plastic analysis are shown in Tables 6 and 7. They are mainly based on Tamagnini's (1993) recommendation and the mean values from the previous studies (Calabresi, et al., 1992; Burland and Potts, 1995; Mitchell and Soga, 1995). Table 8 lists the values of creep parameters. In both elasto-plastic and creep analyses, elastic models were used for the sand and silty sand layers. Rampello and Callisto (1998) obtained the $C_{\mathrm{c}}$ and $C_{\alpha}$ values for the sandy silt layer 
based on triaxial tests of high quality samples. $C_{\mathrm{c}}$ and $C_{\alpha}$ were found to be in the range of 0.3 and 0.003 for the sandy silt layer and 0.9 and 0.02 for the clay layer. It is seen that the clay layer is much more compressible than the sandy silt layer and shows considerably more time dependent deformation. Therefore, elastic model can be used for the sandy silt layer.

The loading sequence consists of a switch on gravity process to generate the pre-existing stress field before the construction of the tower and subsequent stage loading due to the construction of the tower. In order to obtain a more accurate initial stress state, the switch on gravity process was applied in 10 increments with $10 \%$ of the gravity load in each increment. Then, displacements and strains were both set to zero to give the initial configuration of the soil foundation the same as the field. The tower loads corresponding to different construction stages were applied to the initial in-situ stress conditions as four distinct individual loading cases corresponding to the years $1173,1272,1360$, and 1990, respectively. For each loading step, a time value based on the real history was added to let the soil creep. The time period for each stage was specified in terms of years.

\section{Stress Distributions in the Pisa Soil}

Results from the elasto-plastic analysis show that the shear stresses in the upper and intermediate clay layers

Table 5. Soil parameters for elastic analysis

\begin{tabular}{l|c|c|c|c}
\hline \multicolumn{1}{c|}{ Layer } & elevation $(\mathrm{m})$ & $\begin{array}{c}G^{*} \\
(\mathrm{MPa})\end{array}$ & $\begin{array}{c}E^{* *} \\
(\mathrm{MPa})\end{array}$ & $v$ \\
\hline Made ground MG & +3 to +0.7 & 13.44 & 22.0 & 0.30 \\
Clayey silts $\mathrm{A}_{1}$ and $\mathrm{A}_{1}^{\prime}$ & variable & 13.44 & 11.0 & 0.30 \\
Upper Pancone clay $\mathrm{B}_{1}-\mathrm{B}_{3}$ & -7.4 to -17.8 & 10.27 & 23.0 & 0.30 \\
Intermediate clays $\mathrm{B}_{4}-\mathrm{B}_{5}$ & -17.8 to -22.0 & 15.18 & 34.0 & 0.30 \\
Lower clays $\mathrm{B}_{7}-\mathrm{B}_{10}$ & -24.4 to -37.0 & 22.32 & 50.0 & 0.30 \\
\hline Layer & elevation (m) & $E(\mathrm{MPa})$ & $v$ \\
\hline Upper grey sands $\mathrm{A}_{1}^{\prime \prime}, \mathrm{A}_{2}$ & variable & \multicolumn{2}{|c}{13.0} & 0.30 \\
Intermediate sands B6 & -22.0 to -24.4 & 18.0 & 0.30 \\
\hline
\end{tabular}

* - average value from Calabresi et al. (1992) TAB 5.XIV; $* *-E=2(1+v) * G$. are at a level of $50 \%$ to $60 \%$ of their shear strength. Therefore, the Singh and Mitchell creep equation can be used for these layers. However, the stress level in Formation A is very high. Part of the area is already in a state of failure. These layers are believed to have a major influence on the tilting of the tower. The Singh and Mitchell equation may under-predict the amount of creep strain in these high stress layers.

Stress contours of $p^{\prime}$ and $q$ corresponding to the years 1178 and 1990 are plotted in Figs. 15 to 18 . Figures 15 and 16 represent the results from no-creep analysis and Figs. 17 and 18 represents the results from creep analysis. By comparing these results, it can be seen that due to creep, mean effective stresses concentrate more in the clay layers. They are increased by $20 \%$ in the upper clay lay-

Table 7. Soil parameters for sand layers

\begin{tabular}{c|l|c|c|c|c}
\hline $\begin{array}{c}\text { Material } \\
\text { No. }\end{array}$ & \multicolumn{1}{|c|}{ Layer } & $\begin{array}{c}\gamma \\
\left(\mathrm{kN} / \mathrm{m}^{2}\right)\end{array}$ & $\begin{array}{c}E^{*} \\
(\mathrm{MPa})\end{array}$ & $v^{*}$ & $\Phi^{\prime}$ \\
\hline 3 & Silty sand $\mathrm{A}_{1}^{\prime \prime}$ & 8.39 & 13.0 & 0.12 & 34 \\
4 & Upper grey sand $\mathrm{A}_{2}$ & 8.39 & 13.0 & 0.12 & 34 \\
10 & Intermediate sand $\mathrm{B}_{6}$ & 9.29 & 18.0 & 0.12 & 34.3 \\
15 & Rigid footing & 9.09 & $1^{*} 10^{7}$ & 0.12 & - \\
\hline
\end{tabular}

Note: All the rest of materials are clay and clayey silt, they are tabulated in the previous table.

*_from Calabresi et al. (1992) TAB5.XV.

Table 8. Singh and Mitchell parameters (from Mitchell and Soga, 1995)

\begin{tabular}{r|c|c|c|c|c}
\hline Sample & Layer & $\bar{\alpha}$ & $m$ & $\begin{array}{c}A^{\prime} \\
(\% / \mathrm{min})\end{array}$ & $\begin{array}{c}A \\
(\% / y e a r)\end{array}$ \\
\hline $4 \mathrm{~m}$ & Clayey silt $\mathrm{A}_{1}$ & 5.81 & 0.89 & $2.12^{*} 10^{-2}$ & $9.03^{*} 10^{-2}$ \\
$6 \mathrm{~m}$ & Clayey silt $\mathrm{A}_{1}^{\prime}$ & 5.86 & 0.95 & $2.19^{*} 10^{-2}$ & $4.23^{*} 10^{-2}$ \\
$10 \mathrm{~m}$ & Upper clay $\mathrm{B}_{1}$ & 6.33 & 0.83 & $1.62^{*} 10^{-2}$ & $15.21^{*} 10^{-2}$ \\
$14 \mathrm{~m}$ & Upper clay $\mathrm{B}_{2}$ & 6.39 & 0.86 & $8.35^{*} 10^{-3}$ & $5.279^{*} 10^{-2}$ \\
$19 \mathrm{~m}$ & Upper clay $\mathrm{B}_{3}$ & 8.82 & 0.75 & $2.15^{*} 10^{-3}$ & $5.789^{*} 10^{-2}$ \\
\hline
\end{tabular}

Note: $\mathrm{A}=\mathrm{A}^{\prime *}\left(365^{*} 24^{*} 60\right)^{(1-\mathrm{m})} . \mathrm{A}^{\prime}$ has unit of $\% / \mathrm{min}$, to convert $\mathrm{A}^{\prime}$ to $\% /$ year, multiply by $\left(365^{*} 24^{*} 60\right)$. The unit of time is in minutes, therefore divide by $\left(365^{*} 24^{*} 60\right)^{\mathrm{m}}$ to convert $t_{\mathrm{d}}$ to unit of year.

Due to the lack of creep test data, and the fact that layer $B_{3}$ is highly structured soil, creep parameters from layer $\mathrm{B}_{2}$ were assumed to represent those of $\mathrm{B}_{4}$ to $\mathrm{B}_{10}$.

Table 6. Cam-clay parameters for clay layers

\begin{tabular}{|c|c|c|c|c|c|c|c|c|c|c|}
\hline $\begin{array}{c}\text { Material } \\
\text { No. }\end{array}$ & Layer & $\gamma\left(\mathrm{kN} / \mathrm{m}^{2}\right)$ & $C_{\mathrm{c}}$ & $C_{\mathrm{r}}$ & $\Phi^{\prime}$ (degree) & $e_{\mathrm{a}}$ & $a$ & $b$ & $R_{\mathrm{f}}$ & $\mathrm{C}_{\alpha}$ \\
\hline 1 & Made ground MG & 9.09 & 0.205 & 0.021 & 33.67 & 1.290 & 0.0046 & 1.220 & 0.89 & 0.0051 \\
\hline 2 & Clayey silts $A_{1}$ and $A_{1}^{\prime}$ & 9.09 & 0.205 & 0.021 & 33.67 & 1.290 & 0.0046 & 1.220 & 0.89 & 0.0051 \\
\hline 5 & Upper Pancone clay $B_{1}$ & 7.32 & 0.615 & 0.081 & 26.54 & 2.730 & 0.0063 & 1.548 & 0.89 & 0.0154 \\
\hline 6 & Upper Pancone clay $\mathrm{B}_{2}$ & 7.32 & 0.615 & 0.081 & 26.54 & 2.730 & 0.0038 & 1.548 & 0.89 & 0.0154 \\
\hline 7 & Upper Pancone clay $\mathrm{B}_{3}$ & 7.32 & 0.615 & 0.081 & 26.54 & 2.730 & 0.0057 & 1.548 & 0.89 & 0.0154 \\
\hline 8 & Intermediate clays $\mathrm{B}_{4}$ & 10.21 & 0.297 & 0.062 & 28.62 & 1.524 & 0.0095 & 1.351 & 0.89 & 0.0059 \\
\hline 9 & Intermediate clays $\mathrm{B}_{5}$ & 10.21 & 0.297 & 0.062 & 28.62 & 1.524 & 0.0055 & 1.351 & 0.89 & 0.0059 \\
\hline 11 & Lower clay $B_{7}$ & 9.21 & 0.421 & 0.053 & 25.84 & 2.053 & 0.0051 & 1.538 & 0.89 & 0.0098 \\
\hline 12 & Lower clays $B_{8}$ & 9.21 & 0.421 & 0.053 & 25.84 & 2.053 & 0.0039 & 1.650 & 0.89 & 0.0098 \\
\hline 13 & Lower clays $B_{9}$ & 9.21 & 0.421 & 0.053 & 25.84 & 2.053 & 0.0039 & 1.650 & 0.89 & 0.0098 \\
\hline 14 & Lower clays $B_{10}$ & 9.21 & 0.421 & 0.053 & 25.84 & 2.053 & 0.0039 & 1.650 & 0.89 & 0.0098 \\
\hline
\end{tabular}

Note: Material No. 3, 4, and 10 are sand layers, they are tabulated in the next table. 


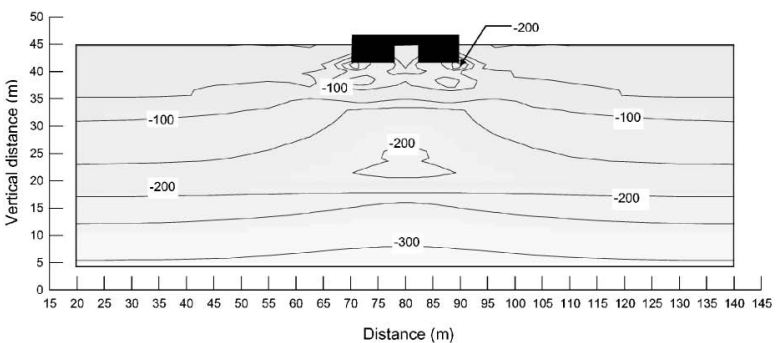

(a)

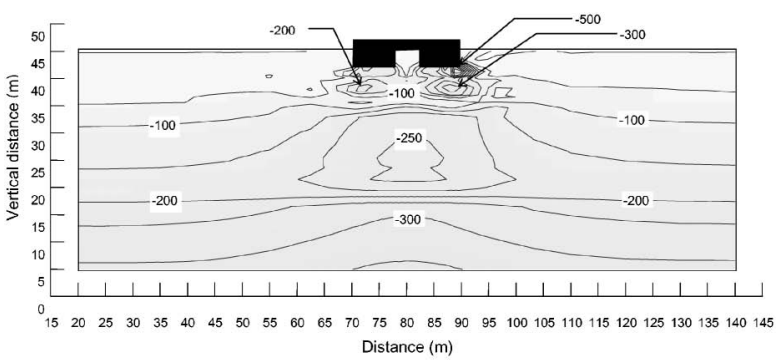

(b)

Fig. 15. Mean stress contours (elasto-plastic analysis): (a) year 1173 and (b) year 1990
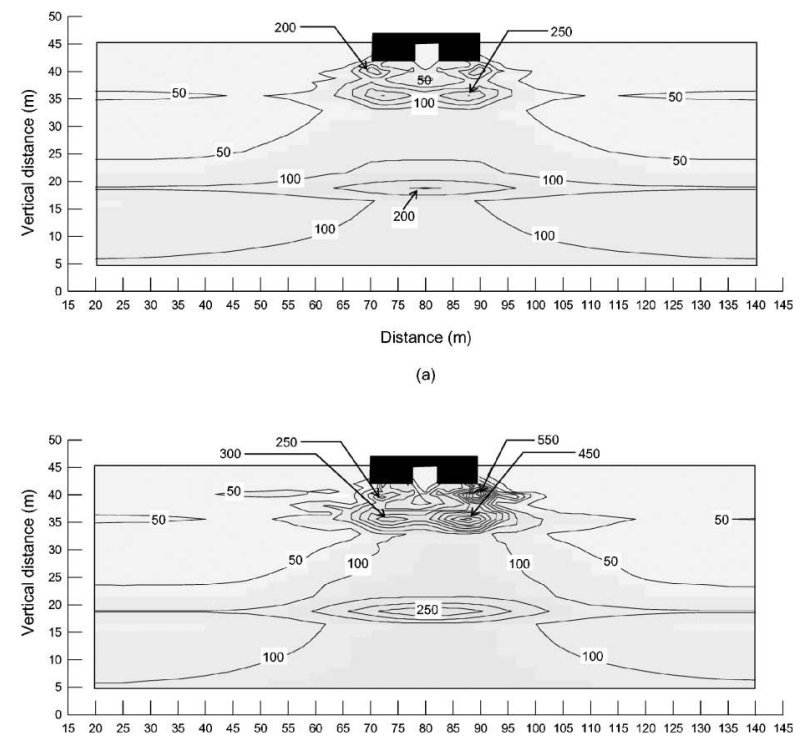

Distance (m)

Fig. 16. Deviatoric stress contours (elasto-plastic analysis): (a) year 1173 and (b) year 1990

ers. Thus, substantial settlement can be expected. Creep also has a significant effect on the deviatoric stresses. It decreases the deviatoric stresses in the clay layers, but increases in the sand layers, which may cause yielding in the sandy soils.

The stress paths of two points, at $6.5 \mathrm{~m}$ and $12 \mathrm{~m}$ depths, located at $10 \mathrm{~m}$ south from the centre of the tower are plotted in Fig. 19. Stress ratios from the elastic analysis are greater than the yielding ratio, which means that some soils are no longer in an elastic state. Figure 19 clearly indicates that plasticity and creep cause the in-

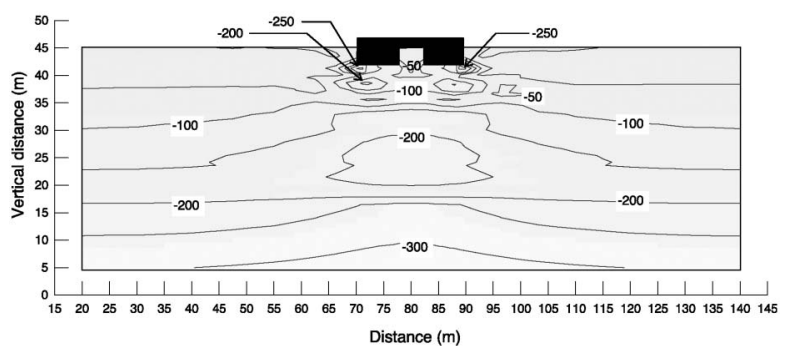

Distance (m)

(a)

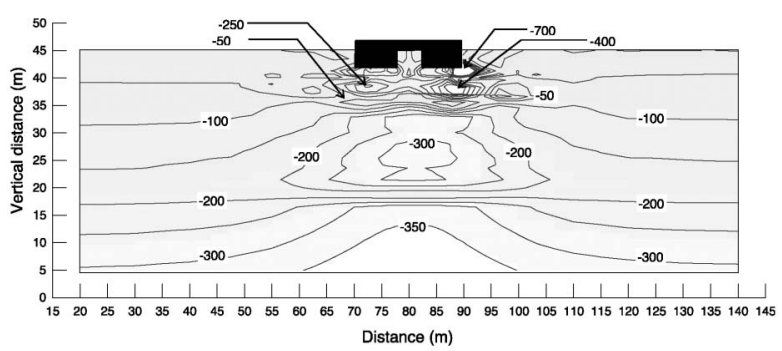

Fig. 17. Mean stress contours (visco-plastic analysis): (a) year 1173 and (b) year 1990

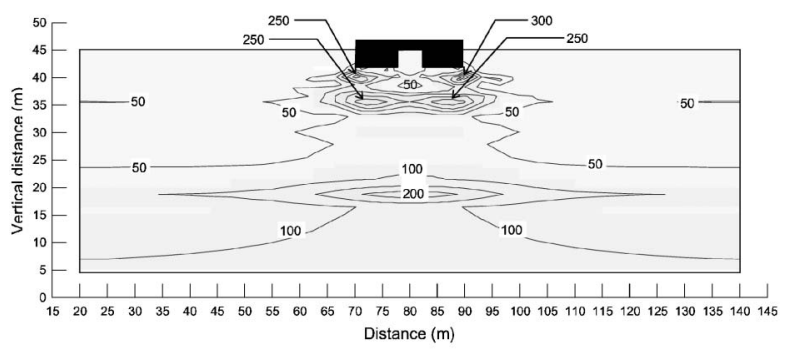

(a)

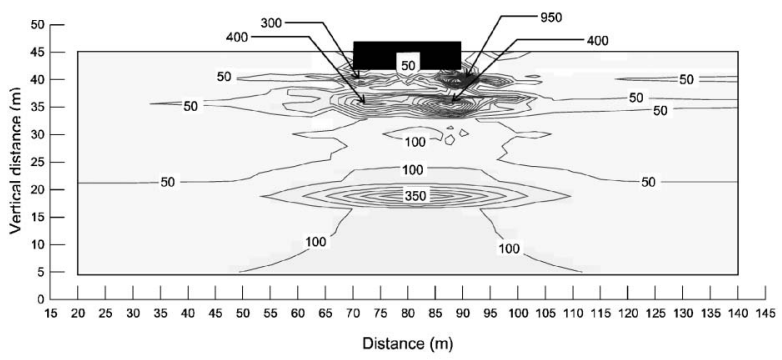

Fig. 18. Deviatoric stress contours (visco-plastic analysis): (a) year 1173 and (b) year 1990

crease of mean effective stresses and the decrease of deviatoric stresses. Thus, the stress states in the clay layers move away from the critical state. This phenomenon has also been observed by Morsy (1994).

\section{Displacements of the Footing}

The calculated final vertical displacements of the footing from creep analysis together with non-creep case are plotted in Fig. 20. A final settlement of $3.3 \mathrm{~m}$ and a tilting angle of 3.4 degrees are obtained after taking the effect of creep into consideration. Creep has caused one meter of additional settlement and 1.7 degrees of additional tilt- 


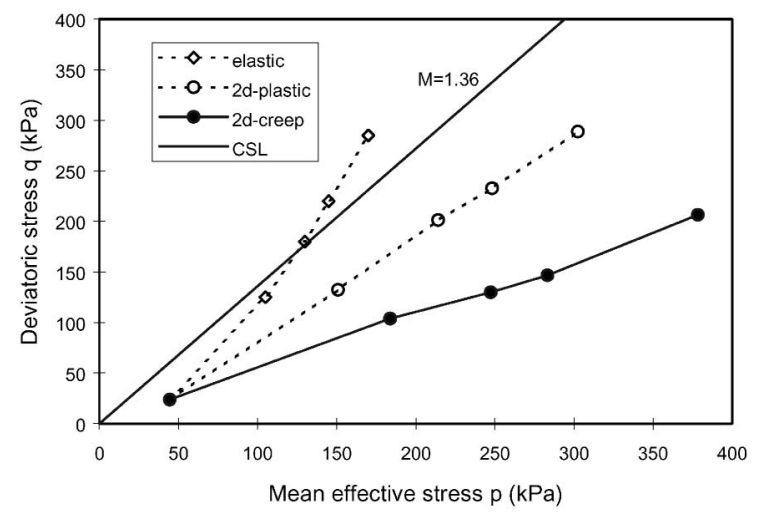

Fig. 19(a). Stress path at $6.5 \mathrm{~m}$ depth at a location $10 \mathrm{~m}$ south from the center of the tower

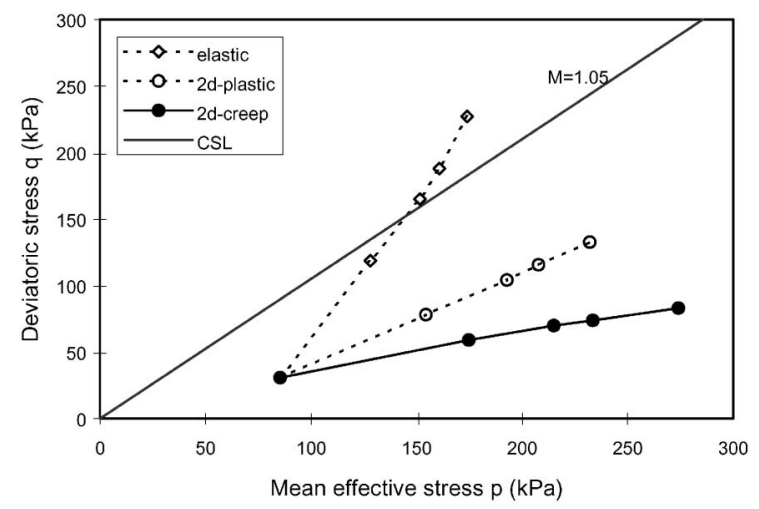

Fig. 19(b). Stress path at $12 \mathrm{~m}$ depth at a location $10 \mathrm{~m}$ south from the center of the tower

ing. However, the calculated settlement is slightly larger than the estimated value of $3.0 \mathrm{~m}$ and the angle of tilting is smaller than the observed 5.5 degrees.

The calculated tilting is plotted against time in Fig. 21(a) together with the observed data given by Jamiolkowski et al. (1993). The calculated settlement at the footing centre is plotted in Fig. 21(b) together with the total estimated settlement since no settlement history is available for comparison. Figure 21 reveals that the tilting was mainly accumulated after the construction stage and the settlement was mainly accumulated during the construction stages, especially in the first stage. The calculated tilting can match history during the construction stage, but underpredict the tilting angle after the year 1550. The northward leaning cannot be simulated, although it is reported to have occurred during the first construction stage.

The deformation process of the tower can be generally divided into two stages: immediate deformation and creep. The immediate deformation of sandy layers was significant compared with its subsequent creep, which caused the northward leaning. The model could not simulate this deformation characteristic well. During and immediately after completion of construction, the soil underneath the tower was mainly creeping. Thus, the creep model can predict the history of tilting reasonably well.

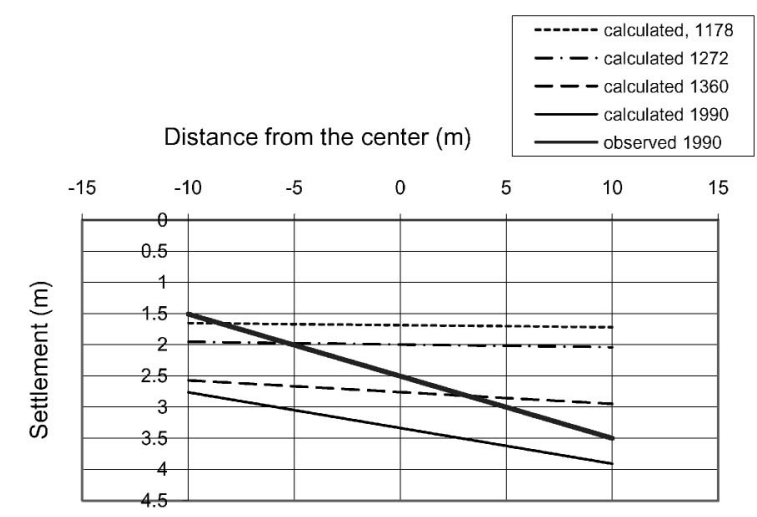

Fig. 20(a). Settlement of the footing $\left(C F=24, I_{c}=1.27\right.$, visco-plastic analyses)

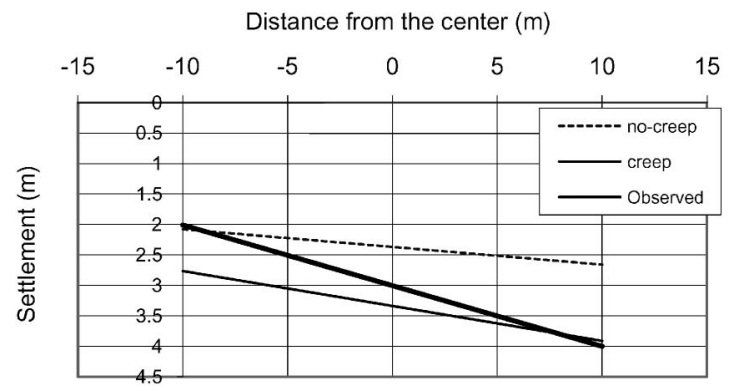

Fig. 20(b). Comparison of the final settlement of the footing $(C F=24$, $\left.I_{\mathrm{c}}=\mathbf{1 . 2 7}\right)$

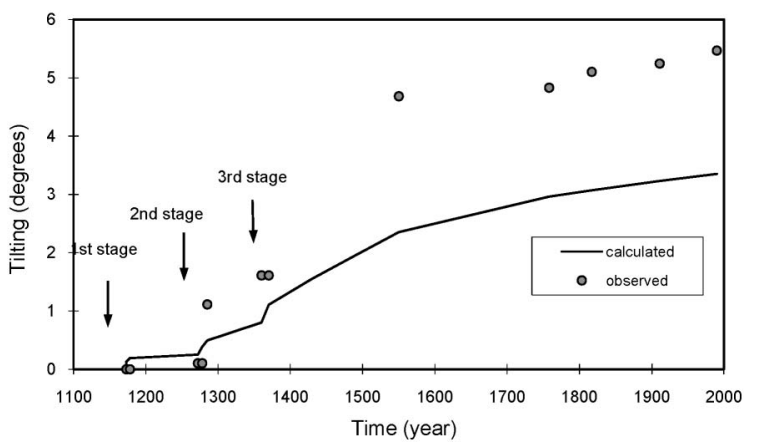

Fig. 21(a). Tilting history of the tower

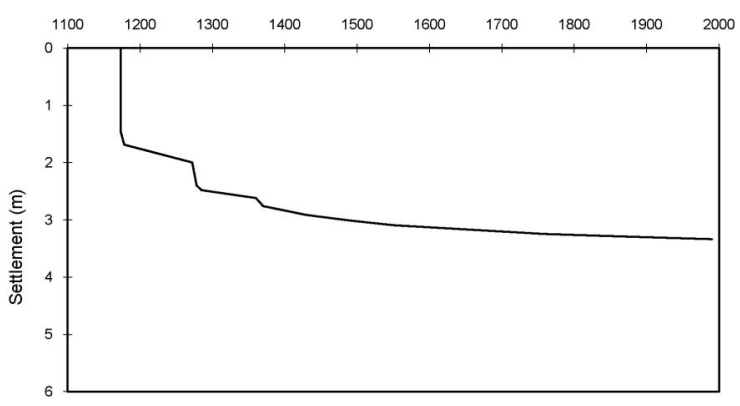

Fig. 21(b). Settlement versus time relationship 
As time progresses, the creep strain rate decreases and finally reduces to zero since the tower is under drained conditions, in which creep rupture is not possible for normally consolidated soil (Mitchell, 1992). On the other hand, other mechanisms such as leaning instability might also exist, which may contribute to considerable amount of tilting. Since the leaning instability mechanism could occur only after the tower reached its full height, it might be the reason which accounts for the abrupt increase in the tilting angle immediately after the construction, as shown in Fig. 21(a). Since the tower has been in a very critical condition close to failure, it is very sensitive to very small disturbances, such as dewatering, foundation excavation and solar heating and daily temperature fluctuation. Throughout the tower's history, there might have been physical disturbances which led to an increase in tiling, approximately around AD 1300 and between AD 1400-1500, which may account for the discrepancies between the calculated and observed tiling of the tower.

\section{SENSITIVITY ANALYSES OF MODEL PARAMETERS}

Since the above analyses were performed mainly based on the mean values of the model parameters, it is of interest to explore the degree that these parameters affect the calculated deformation. On the other hand, as mentioned by Brandes et al. (1996), it should be kept in mind that the model parameters do not act independently. The sensitivity of these parameters could be less significant than the results shown in this study if the dependence of these parameters on each other were considered.

\section{Selection of Model Parameters}

The sensitivity analysis was focused on the parameters from the clayey silt layer $A_{1}$ and the upper clay layer $B_{1}$ (see Fig. 2) due to their scatter nature and the significance on the deformation behaviour of the tower. Among the seven time-independent parameters, only four parameters, $C_{\mathrm{c}}, \phi^{\prime}, R_{\mathrm{f}}$, and $e_{\mathrm{a}}$, were selected for the sensitivity study. The influence of the recompression index $C_{\mathrm{r}}$ is not expected to be significant, since Pisa soil is mainly subjected to loading. Parameter a is the reciprocal of the initial tangent modulus, it is not sensitive in the stress strain relationship. Hyperbolic parameter $b$ depends on $C_{\mathrm{r}}, C_{\mathrm{c}}$, $M$, and $R_{\mathrm{f}}$.

Volumetric and deviatoric creep components may be both important in the Pisa soil, since the tower load could increase both mean effective stresses and deviatoric stresses by one order of magnitude from their initial values, as shown in Fig. 19. The sensitivity of the secondary compression coefficient $C_{\alpha}$ and the Singh and Mitchell creep parameters $A, m$ and $\bar{\alpha}$ were investigated. Creep tests on Pisa clay (Bishop and Lovenbury, 1969; Mitchell and Soga, 1995) showed that creep effects in layers $A_{1}$ and $B_{1}$ were significant in comparison with the rest of the layers. Therefore, sensitivity analyses of the time-dependent parameters $C_{\alpha}, A, m$, and $\bar{\alpha}$ were also limited to the layers $\mathrm{A}_{1}$ and $\mathrm{B}_{1}$.

The possible practical ranges of model parameters that are necessary for sensitivity study are shown in Table 9. The maximum and minimum values were determined based on most probable values of the parameters for the soil type from practical experience. The range of values vary from less than $10 \%$ to over $50 \%$, depending on the parameter. Creep analysis conducted in the previous sec-

(a) Layer $A_{1}$

Table 9. Possible range of soil parameters

\begin{tabular}{|c|c|c|c|c|c|c|c|c|c|c|c|c|c|c|c|c|}
\hline \multirow{2}{*}{ Parameter } & \multicolumn{2}{|c|}{$C_{\mathrm{c}}$} & \multicolumn{2}{|c|}{$\phi$ (degree) } & \multicolumn{2}{|c|}{$e_{\mathrm{a}}$} & \multicolumn{2}{|c|}{$R_{\mathrm{f}}$} & \multicolumn{2}{|c|}{$C_{\alpha}$} & \multicolumn{2}{|c|}{$A$ (/year) } & \multicolumn{2}{|c|}{$m$} & \multicolumn{2}{|c|}{$\bar{\alpha}$} \\
\hline & value & $\Delta$ & value & $\Delta$ & value & $\Delta$ & value & $\Delta$ & value & $\Delta$ & value & $\Delta$ & value & $\Delta$ & value & $\Delta$ \\
\hline $\begin{array}{l}\text { min } \\
\text { mean } \\
\text { max. }\end{array}$ & $\begin{array}{l}0.161 \\
0.205 \\
0.299\end{array}$ & $\begin{array}{l}-21 \% \\
* \\
+46 \%\end{array}$ & $\begin{array}{l}30.92 \\
33.67\end{array}$ & $\begin{array}{c}-8 \% \\
*\end{array}$ & 0.71 & $\begin{array}{c}-45 \% \\
*\end{array}$ & $\begin{array}{l}0.7 \\
0.89 \\
1.0\end{array}$ & $\begin{array}{l}-21 \% \\
* \\
+12 \%\end{array}$ & $\begin{array}{l}0.0041 \\
0.0051 \\
0.0137\end{array}$ & $\begin{array}{c}-20 \% \\
* \\
+169 \%\end{array}$ & $\begin{array}{l}0.000423 \\
0.000903\end{array}$ & $\begin{array}{c}-53 \% \\
*\end{array}$ & $\begin{array}{l}0.77 \\
0.89 \\
0.96\end{array}$ & $\begin{array}{c}-13 \% \\
* \\
+8 \%\end{array}$ & $\begin{array}{l}5.07 \\
5.81 \\
6.29\end{array}$ & $\begin{array}{c}12.7 \% \\
* \\
+8 \%\end{array}$ \\
\hline
\end{tabular}

(b) Layer $\mathrm{B}_{1}$

\begin{tabular}{|c|c|c|c|c|c|c|c|c|c|c|c|c|c|c|c|c|}
\hline \multirow{2}{*}{ Parameter } & \multicolumn{2}{|c|}{$C_{\mathrm{c}}$} & \multicolumn{2}{|c|}{$\phi$ (degree) } & \multicolumn{2}{|c|}{$e_{\mathrm{a}}$} & \multicolumn{2}{|c|}{$R_{\mathrm{f}}$} & \multicolumn{2}{|c|}{$C_{\alpha}$} & \multicolumn{2}{|c|}{$A$ (/year) } & \multicolumn{2}{|c|}{$m$} & \multicolumn{2}{|c|}{$\bar{\alpha}$} \\
\hline & value & $\Delta$ & value & $\Delta$ & value & $\Delta$ & value & $\Delta$ & value & $\Delta$ & value & $\Delta$ & value & $\Delta$ & value & $\Delta$ \\
\hline $\begin{array}{l}\text { min } \\
\text { mean } \\
\text { max. }\end{array}$ & $\begin{array}{l}0.507 \\
0.615 \\
1.0\end{array}$ & $\begin{array}{c}-18 \% \\
* \\
+63 \%\end{array}$ & $\begin{array}{l}24.44 \\
26.54\end{array}$ & $\begin{array}{c}-8 \% \\
*\end{array}$ & $\begin{array}{l}2.67 \\
2.73\end{array}$ & $\begin{array}{c}-2 \% \\
*\end{array}$ & $\begin{array}{l}0.7 \\
0.89 \\
1.0\end{array}$ & $\begin{array}{l}-21 \% \\
* \\
+12 \%\end{array}$ & $\begin{array}{l}0.0075 \\
0.0154 \\
0.0615\end{array}$ & $\begin{array}{c}-51 \% \\
* \\
+299 \%\end{array}$ & 0.001521 & $*$ & $\begin{array}{l}0.78 \\
0.83 \\
0.86\end{array}$ & $\begin{array}{l}-6 \% \\
* \\
+4 \%\end{array}$ & $\begin{array}{l}5.50 \\
6.33 \\
9.00\end{array}$ & $\begin{array}{l}-13 \% \\
* \\
+42 \%\end{array}$ \\
\hline
\end{tabular}

Table 10. Soil parameters used in FEA analyses

\begin{tabular}{l|c|c|c|c|c|c|c|c|c|c|c|c|c|c|c|c}
\hline \multicolumn{1}{c|}{ Layer } & \multicolumn{10}{c}{$\mathrm{A}_{\mathrm{c}}$} \\
\hline Parameters & $C_{\mathrm{c}}$ & $\phi($ degree $)$ & $R_{\mathrm{f}}$ & $e_{\mathrm{a}}$ & $C_{\alpha}$ & $A(/$ year $)$ & $m$ & $\bar{\alpha}$ & $C_{\mathrm{c}}$ & $\phi$ (degree) & $R_{\mathrm{f}}$ & $e_{\mathrm{a}}$ & $C_{\alpha}$ & $A(/$ year $)$ & $m$ & $\bar{\alpha}$ \\
\hline used & 0.205 & 33.67 & 0.89 & 1.29 & 0.0051 & 0.000903 & 0.89 & 5.81 & 0.615 & 26.54 & 0.89 & 2.730 & 0.0154 & 0.001521 & 0.83 & 6.33 \\
$10 \%$ change & 0.226 & 30.30 & 0.80 & 1.419 & 0.0056 & 0.000993 & 0.80 & 6.39 & 0.678 & 23.89 & 0.80 & 3.003 & 0.0169 & 0.00167 & 0.747 & 6.96 \\
\hline
\end{tabular}


Table 11. Parameter sensitivity analyses results

\begin{tabular}{|c|c|c|c|c|c|c|c|c|}
\hline Layer & \multicolumn{4}{|c|}{$\mathrm{A}_{1}$} & \multicolumn{4}{|c|}{$\mathrm{B}_{1}$} \\
\hline \multirow{2}{*}{ Items } & \multicolumn{2}{|c|}{ Settlement (m) } & \multicolumn{2}{|c|}{ Tilting angle (degree) } & \multicolumn{2}{|c|}{ Settlement (m) } & \multicolumn{2}{|c|}{ Tilting angle (degree) } \\
\hline & FEA result & change $(\%)$ & FEA result & change $(\%)$ & FEA result & change (\%) & FEA result & change $(\%)$ \\
\hline Reference & 3.34 & - & 3.35 & - & 3.34 & - & 3.35 & - \\
\hline$C_{\mathrm{c}}(+10 \%)$ & 3.43 & +2.7 & 3.48 & +3.8 & 3.40 & +1.9 & 3.37 & +0.6 \\
\hline$\phi^{\prime}(-10 \%)$ & 3.37 & +0.9 & 3.57 & +6.5 & 3.36 & +0.7 & 3.39 & +1.2 \\
\hline$R_{\mathrm{f}}(-10 \%)$ & 3.36 & +0.8 & 3.48 & +4.0 & 3.35 & +0.3 & 3.41 & +1.7 \\
\hline$e_{\mathrm{a}}(+10 \%)$ & 3.31 & -0.8 & 3.29 & -1.9 & 3.29 & -1.6 & 3.31 & -1.4 \\
\hline$C_{\alpha}(+10 \%)$ & 3.34 & 0 & 3.38 & +0.8 & 3.34 & +0.1 & 3.37 & +0.5 \\
\hline$A(+10 \%)$ & 3.35 & +0.3 & 3.40 & +1.3 & 3.34 & +0.1 & 3.36 & +0.2 \\
\hline$m(-10 \%)$ & 3.41 & +2.2 & 3.61 & +7.6 & 3.37 & +0.9 & 3.45 & +3.0 \\
\hline $\bar{\alpha}(+10 \%)$ & 3.40 & +1.8 & 3.56 & +6.1 & 3.35 & +0.5 & 3.33 & -0.8 \\
\hline
\end{tabular}

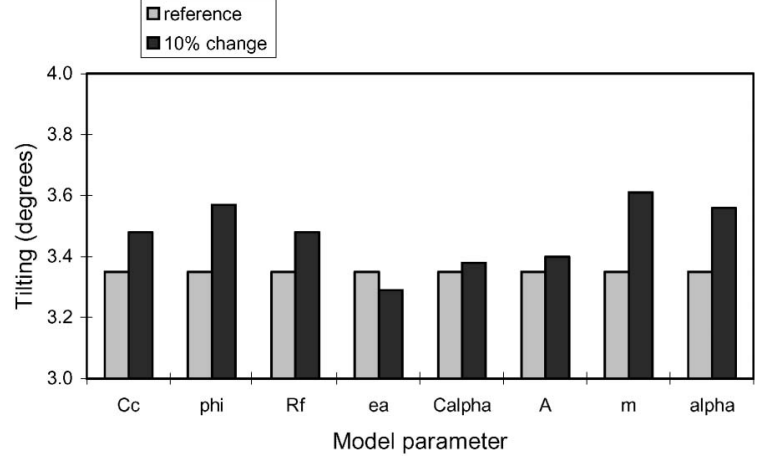

Fig. 22(a). Sensitivity of model parameters in terms of final inclination

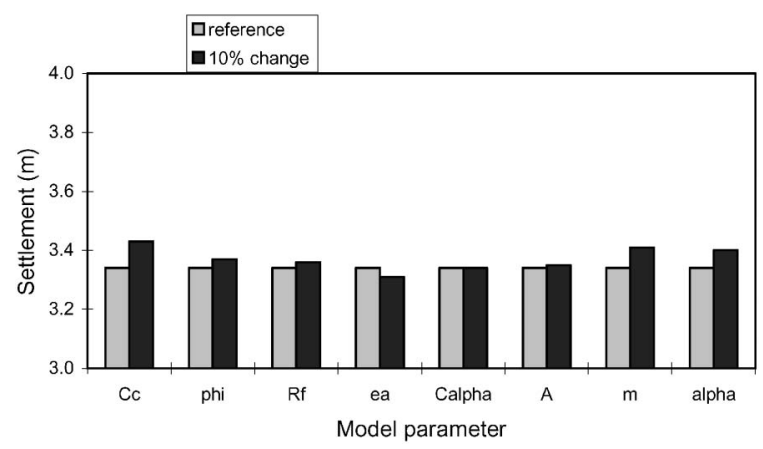

Fig. 22(b). Sensitivity of model parameters in terms of final settlement

tion was chosen as a reference case in the discussion. The sensitivity analyses were done by taking a $10 \%$ change of each reference value as shown in Table 10. Ten percent change from each reference value is considered to be appropriate and it should provide an insight on the tilting of the tower. Overly large variations can produce unrealistic effects while excessively small changes make it difficult to examine its impact. The results of the parametric variation are shown in Table 11 and Fig. 22.

\section{Discussions}

Table 11 indicates that model parameters of layer $\mathrm{A}_{1}$ are more sensitive than those of layer $B_{1}$ in the deformation behaviour of the Pisa soil, although creep in layer $\mathrm{B}_{1}$ is more significant in comparison with the rest of the layers. This suggests that model parameters become more sensitive under high stress levels than low stress levels. Increasing the accuracy of the parameters of layer $A_{1}$ could improve the accuracy of the FEA results.

Figure 22 summarises the results in terms of the final inclination and settlement under changes of material parameters in layer $\mathrm{A}_{1}$. The difference in the final settlement is within $2.7 \%$ and tilting angle $7.6 \%$ of their reference values under a $10 \%$ change of model parameters. The difference could be even lower if the dependence of these parameters on each other is considered. This suggests that the deformation behaviour of the Pisa foundation may not be controlled by any specific parameter. It is the combination of all the time-independent as well as time-dependent parameters in the model.

Among the model parameters, the angle of internal friction $\phi^{\prime}$ and the Singh and Mitchell parameters $m$ and $\bar{\alpha}$ are relatively sensitive in terms of the tilting angle. A $10 \%$ decrease of $\phi^{\prime}$ value causes a $6.5 \%$ increase in the tilting angle. A $10 \%$ decrease of $\mathrm{m}$ results in a $7.6 \%$ increase in tilting, while a $10 \%$ increase of $\bar{\alpha}$ results in a 6.1 $\%$ increase in tilting.

\section{SUMMARY AND CONCLUSION}

A time-dependent constitutive model has been adopted to investigate the deformation characteristics of the soil underneath the Pisa Tower. In the model, strain tensors are decomposed into immediate and delayed or creep components, which are further decomposed into volumetric and deviatoric components. The double-yield criteria defined by the ellipsoid MCCM and the VonMises cylinder inscribed in the ellipsoid is incorporated to evaluate both the time-independent and time-dependent strain components.

The numerical analyses conducted under non-creep and creep conditions have concluded that creep is one of the major important factors that cause the tilting of the tower. Because of the creep, mean effective stresses increase by $20 \%$ in upper clay layers and the stress states move away from the critical state. Deviatoric stresses are more concentrated in the sand layers and directly below the footing. Creep causes an additional one-meter settle- 
ment and 1.7 degrees additional tilting. The calculated settlement is larger than the estimated value and the calculated tilting angle is smaller than the measured one.

Comparing the calculated tilting history with the estimated one, one can see that creep may be an important factor during and right after the construction stages. Apart from that, other factors may have contributed to the tilting of the tower, such as leaning instability, solar heating, and other perturbations, but these cannot be quantified in the current model.

\section{ACKNOWLEDGMENT}

Financial support provided by the National Science and Engineering Council of Canada is gratefully acknowledged.

\section{REFERENCES}

1) Bai, J. (1998): Creep analyses of the Leaning Tower of Pisa, Ph.D. Thesis, University of Alberta, Edmonton.

2) Barden, L. (1965): Consolidation of clay with non-linear viscosity, Geotechnique, 15(4), 345-362.

3) Barden, L. (1969): Time dependent deformation of normally consolidated clays and peats, ASCE Journal of Soil Mechanics and Foundation Engineering Division, 95(SM1), 1-31.

4) Bishop, A. E. and Lovenbury, H. T. (1969): Creep characteristics of two undisturbed clays, Proc. ICSMFE, 1, 29-37.

5) Borja, R. I. and Kavazanjian, E. Jr. (1985): A constitutive model for the stress-strain-time behaviour of 'wet' clays, Geotechnique, 35(3), 283-298.

6) Borja, R. I., Hsieh, H. S. and Kavazanjian, E. Jr. (1990): Doubleyield-surface model, II: Implementation and verification, $A S C E$ Journal of the Geotechnical Engineering Division, 116(GT9), 1402-1421.

7) Brandes, H. G., Silva, A. J., Sadd, M. H. and Veyera, G. E. (1994): Stress-strain-time modelling of submarine slopes, Proc. 8th Int. Conf. on Computer Methods and Advances in Geomechanics, 3, 2435-2445.

8) Brandes, H. G., Sadd, M. H. and Silva, A. J. (1996): Finite element modelling of a deep sea clay in long-term laboratory creep tests, International Journal for Numerical and Analytical Methods in Geomechanics, 20, 887-905.

9) Buisman, K. (1940): Grondmechanica, Delft, Waltman.

10) Burland, J. B. and Potts, D. M. (1995): Development and application of a numerical model for the Leaning Tower of Pisa, Special Lecture, International Symposium on Pre-Failure Deformation Characteristics of Geo-Materials, IS-Hokkaido, 715-738.

11) Calabresi, G., Rampello, S. and Callisto, L. (1992): Geotechnical characterisation of the tower's subsoil within the framework of the critical state theory, Universita'di Roma, Dipartimento di Ingegneria Strutturale.

12) Christensen, R. W. and Wu, T. H. (1964): Analysis of clay deformation as a rate process, ASCE Journal of Soil Mechanics and Foundation Engineering Division, 90(SM6), 125-157.

13) De Josselin De Jong (1968): Consolidation models consisting of an assembly of viscous element of a cavity channel network, Geotechnique, 18, 195-228.

14) Eyring, H. (1936): Viscosity, plasticity and diffusion as example of absolute reaction rates, Journal of Chemical Physics, 4, 283-291.

15) Holzer, T. L., Hoeg, K. and Arulanandan, K. (1973): Excess pore pressure during undrained creep, Canadian Geotechnical Journal, 10(1), 12-24.

16) Hsieh, H. S., Kavazanjian, E. Jr. and Borja, R. I. (1990): Doubleyield-surface model, I: Theory, ASCE Journal of the Geotechnical Engineering Division, 116(GT9), 1381-1401.
17) Jamiolkowski, M., Levi, F. and Lancellotta, R. (1993): Leaning Tower of Pisa-updated information, 3rd International Conference on Case Histories in Geotechnical Engineering, St. Louis, Missouri, 2, 1319-1330.

18) Kavazanjian, E. Jr. and Mitchell, J. K. (1980): Time-dependent deformation behaviour of clays, ASCE Journal of the Geotechnical Engineering Division, 106(GT6), 611-630.

19) Kuhn, M. R. and Mitchell, J. K. (1993): New perspectives on soil creep, ASCE Journal of the Geotechnical Engineering Division, 119(GT3), 507-524.

20) Leonards, G. A. (1979): Discussion of "Foundation performance of Tower of Pisa", ASCE Journal of the Geotechnical Engineering Division, 105(GT1), 95-105.

21) Mitchell, J. K. (1964): Shearing resistance of soil as a rate process, ASCE Journal of Soil Mechanics and Foundation Engineering Division, 90(SM1), 29-61.

22) Mitchell, J. K. (1992): Fundamental of Soil Behaviour, Second Edition, John Wiley and Sons, Inc.

23) Mitchell, J. K. and Soga, K. (1995): Numerical and experimental studies related to the performance and stabilisation of the Tower of Pisa, Report to the Consorzio Progetto Torre di Pisa.

24) Mitchell, J. K. Vivatrat, V. and Lambe, T. W. (1977): Foundation performance of Tower of Pisa, ASCE Journal of the Geotechnical Engineering Division, 103(GT3), 227-249.

25) Morsy, M. M. (1994): Effective stress modeling of creep behaviour of clay, Ph.D. Thesis, University of Alberta, Edmonton, Alberta.

26) Morsy, M. M., Morgenstern, N. R. and Chan, D. H. (1995): Simulation of creep deformation in the foundation of Tar Island Dyke, Canadian Geotechnical Journal, 32, 1002-1023.

27) Murayama, S. and Shibata, T. (1958): On the Rheological Characters of Clay, Part 1, Disaster Preventation Research Institute, Koyoto University, Bulletin, 26.

28) Murayama, S. and Shibata, T. (1961): Rheological properties of clay, Proc. 5th ICSMFE, Paris, France, 1, 269-273.

29) PISA ${ }^{\circledR}$ (2007): Program for Incremental Stress Analysis, www.pisa.ab.ca.

30) Rampello, S. and Callisto, L. (1998): A study on the subsoil of the Tower of Pisa based on results from standard and high-quality samples, Canadian Geotechnical Journal, 95(6), 1074-1092.

31) Singh, A. and Mitchell, J. K. (1968): Generalised stress-strain-time function for soil, ASCE Journal of Soil Mechanics and Foundation Engineering Division, 94(SM1), 21-46.

32) Tamagnini, C. (1993): Private communication with Mitchell, J. K.

33) Taylor, D. W. (1948): Fundamentals of Soil Mechanics, New York, Wiley.

34) Terzaghi, K. (1941): Undisturbed clay samples and undisturbed clays, Journal of the Boston Society of Civil Engineering, 15(3), 645-660.

35) Walker, L. K. (1969): Secondary compression in the shear of clays, ASCE Journal of Soil Mechanics and Foundation Engineering Division, 95(SM1), 167-188.

36) Yoshikuni, H., Kusakabe, O., Hirao, T. and Ikegami, S. (1994): Elasto-viscous modeling of time-dependent behaviour of clay, Proc. 13th ICSMFE, New Delhi, India, 1, 417-421.

\section{APPENDIX A}

This appendix presents the derivation of the intrinsic time variables.

a) Volumetric age

Taylor's secondary creep law

$$
\dot{\varepsilon}_{\mathrm{v}}^{\mathrm{t}}=\frac{\psi}{(1+e) t_{\mathrm{v}}}
$$

From the definition of volumetric strain

$$
\dot{\varepsilon}_{\mathrm{v}}=\frac{\dot{e}^{\mathrm{p}}}{(1+e)}
$$


Comparing (A1) and (A2) yields

$$
\dot{e}^{\mathrm{p}}=-\frac{\psi}{t}
$$

Here the negative sign is added because as time progresses, the void ratio tends to decrease.

Integration of (A3) yields

$$
e^{\mathrm{p}}=-\psi \ln t+c
$$

where $c$ is the integration constant.

Let void ratio $e_{2}$ correspond to the reference volumetric time $\left(t_{\mathrm{v}}\right)_{\mathrm{i}}$, associated with the virgin consolidation curve (see Fig. 5). If $t=\left(t_{\mathrm{v}}\right)_{\mathrm{i}}$ and $e^{\mathrm{p}}=e_{2}$, then

$$
c=e_{2}+\psi \ln \left(t_{\mathrm{v}}\right)_{\mathrm{i}}
$$

Substituting this back into (A4) yields

$$
e^{\mathrm{p}}=-\psi \ln \frac{t}{\left(t_{\mathrm{v}}\right)_{\mathrm{i}}}+e_{2}
$$

Let the void ratio $e_{1}$ correspond to the current state with time $t_{\mathrm{v}}$. If $t=t_{\mathrm{v}}$ and $e^{\mathrm{p}}=e_{1}$, then

$$
t_{\mathrm{v}}=\left(t_{\mathrm{v}}\right)_{\mathrm{i}} \exp \left(\frac{\left(e_{2}-e_{1}\right)}{\psi}\right)
$$

b) Deviatoric age

Singh and Mitchell's (1968) creep equation

$$
\dot{\varepsilon}_{\mathrm{d}}^{\mathrm{t}}=A e^{\bar{\alpha} \overline{\mathrm{D}}}\left[\frac{\left(t_{\mathrm{d}}\right)_{\mathrm{i}}}{t_{\mathrm{d}}}\right]^{\mathrm{m}}
$$

Integration of (A8) yields two different mathematical forms

$$
\begin{aligned}
& \varepsilon_{\mathrm{a}}=A \exp (\bar{\alpha} \bar{D})\left(t_{\mathrm{d}}\right)_{\mathrm{i}}^{\mathrm{m}}\left(\frac{1}{1-m}\right) t^{1-\mathrm{m}}+c_{1} \quad \text { for } m \neq 1 \\
& \varepsilon_{\mathrm{a}}=A \exp (\bar{\alpha} \bar{D})\left(t_{\mathrm{d}}\right)_{\mathrm{i}} \ln t+c_{2} \quad \text { for } m=1
\end{aligned}
$$

In three-dimensional case, the above equations become

$$
\begin{aligned}
& \gamma=A \exp (\bar{\alpha} \bar{D})\left(t_{\mathrm{d}}\right)_{\mathrm{i}}^{\mathrm{m}}\left(\frac{1}{1-m}\right) t^{1-\mathrm{m}}+c_{1} \quad \text { for } m \neq 1 \\
& \gamma=A \exp (\bar{\alpha} \bar{D})\left(t_{\mathrm{d}}\right)_{\mathrm{i}} \ln t+c_{2} \text { for } m=1
\end{aligned}
$$

where $\gamma$ is the shear strain. $c_{1}$ and $c_{2}$ are integration constants.

Let shear strain $\gamma_{1}$ correspond to the current state with time $t_{\mathrm{d}}$. Let strain $\gamma_{2}$ correspond to an instant time $\left(t_{\mathrm{d}}\right)_{\mathrm{i}}$ with a hyperbolic relationship on the $q-\gamma$ plane (see Fig. 4)

$$
\gamma_{2}=\frac{q a}{p_{\mathrm{c}}^{\prime} R_{\mathrm{f}}-q b}
$$

For the $m \neq 1$ case, if $t=\left(t_{\mathrm{d}}\right)_{\mathrm{i}}$ and $\gamma=\gamma_{2}$, integration constant $c_{1}$ can be obtained from (A10a) as follows

$$
c_{1}=\gamma_{2}-\frac{A}{1-m} \exp (\bar{\alpha} \bar{D})\left(t_{\mathrm{d}}\right)_{\mathrm{i}}
$$

Substituting $c_{1}$ back into (A10a), and setting $t=t_{\mathrm{d}}$ and $\gamma=$ $\gamma_{1}$, the deviatoric age $t_{\mathrm{d}}$ can be obtained as

$$
t_{\mathrm{d}}=\left[\frac{\left(\gamma_{1}-\gamma_{2}\right)(1-m)}{A \exp (\bar{\alpha} \bar{D})\left(t_{\mathrm{d}}\right)_{\mathrm{i}}^{\mathrm{m}}}+\left(t_{\mathrm{d}}\right)_{\mathrm{i}}^{1-\mathrm{m}}\right]^{1 / 1-\mathrm{m}} \text { for } m \neq 1
$$

For the $m=1$ case, if $t=\left(t_{\mathrm{d}}\right)_{\mathrm{i}}$ and $\gamma=\gamma_{2}$, integration constant $c_{2}$ can be obtained from (A10b) as

$$
c_{2}=\gamma_{2}-A \exp (\bar{\alpha} \bar{D})\left(t_{\mathrm{d}}\right)_{\mathrm{i}} \ln \left(t_{\mathrm{d}}\right)_{\mathrm{i}}
$$

Substituting $c_{2}$ back into (A10b) and let $t=t_{\mathrm{d}}$ and $\gamma=\gamma_{1}$ yields

$$
t_{\mathrm{d}}=\left(t_{\mathrm{d}}\right)_{\mathrm{i}} \exp \left(\frac{\left(\gamma_{1}-\gamma_{2}\right)}{A \exp (\bar{a} \bar{D})\left(t_{\mathrm{d}}\right)_{\mathrm{i}}}\right) \text { for } m=1
$$

